Portland State University

PDXScholar

\title{
An exploration of cultural differences in Japanese/ American intercultural marriages
}

Mary Erzen-Toyoshima

Portland State University

Follow this and additional works at: https://pdxscholar.library.pdx.edu/open_access_etds

Part of the Critical and Cultural Studies Commons, and the International and Intercultural Communication Commons Let us know how access to this document benefits you.

\section{Recommended Citation}

Erzen-Toyoshima, Mary, "An exploration of cultural differences in Japanese/American intercultural marriages" (1986). Dissertations and Theses. Paper 3595.

https://doi.org/10.15760/etd.5479

This Thesis is brought to you for free and open access. It has been accepted for inclusion in Dissertations and Theses by an authorized administrator of PDXScholar. Please contact us if we can make this document more accessible: pdxscholar@pdx.edu. 
AN ABSTRACT OF THE THESIS OF Mary Erzen-Toyoshima for the Master of Arts in Speech Communication presented May 15 , 1986 .

Title: An Exploration of Cultural Differences in Japanese/American Intercultural Marriages.

APPROVED BY MEMBERS OF THE THESIS COMMITTEE:

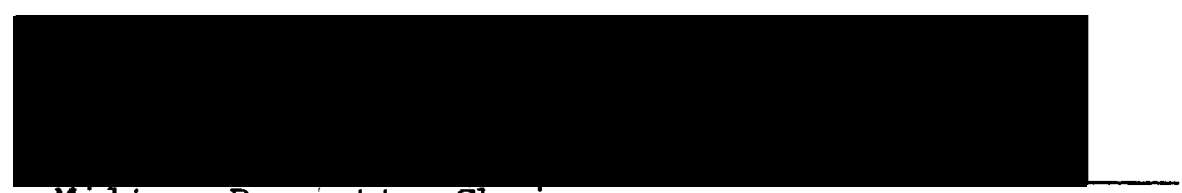

Milton Bennett, Chairman

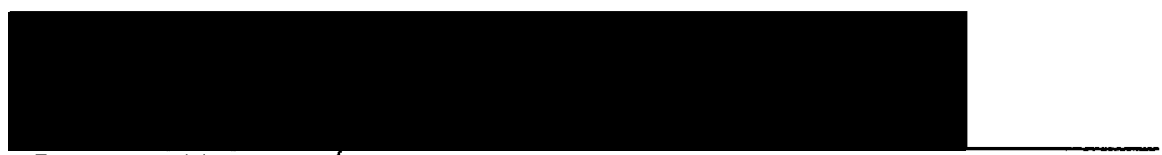

LaRay M. Bą̧ria

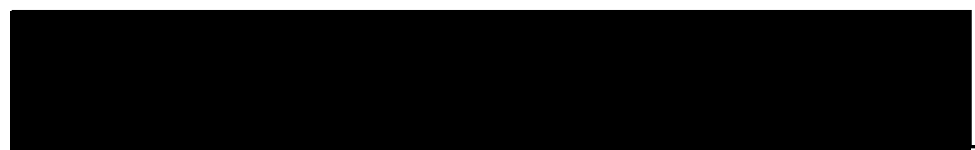

Theodore G. Grove

This is a study of how certain cultural differences between Japanese and Americans might be problematic in Japanese/American intercultural marriage.

Based on a review of the literature about cultural differences between Japanese and Americans, and preliminary interviews of couples, differences that were expected to be particularly problematic in Japanese/American intercultural marriages were selected for this study. Two kinds of 
cultural differences were selected--value differences and communication style differences.

Four value differences were selected-- group orientation versus individual orientation; dependence versus independence; inequality versus equality; and defined sex roles versus undefined sex roles. Three communication style differences were selected-- orientation to interaction (individualistic/objective vs. interpersonal/subjective) code preference (verbal vs. nonverbal), and interaction format (persuasive/quantitative/pragmatic vs . harmonizing/ holistic/process).

Interviews were conducted with the spouses of twelve Japanese/American marriages. Six of the marriages included a Japanese wife and an American husband and the other six included an American wife and a Japanese husband. An analysis of the responses indicated that the selected cultural differences are indeed problematic in the marriages. Though responses about some of the differences are less supportive of the literature than expected, all of them are consistent with the literature in that the Japanese represent Japanese cultural patterns and the Americans represent American cultural patterns. The major finding of this study is that communication style differences are most problematic. The highest degree of difficulty is found to stem from the difference in the American objective view of reality and the Japanese subjective view. The difference in 
code preference, with the Japanese emphasis on nonverbal communication and the American emphasis on verbal communication, also causes a high degree of difficulty and requires a good deal of adjustment within the marriages studied. Among the value differences examined, the difference between the American value of the self and the Japanese value of the group is reported to be problematic. Language, which is often perceived as the major area of difficulty in an intercultural marriage is reported not to present a serious problem.

Suggestions and questions for further research are provided. Application of some of the findings of this study are also given. 
AN EXPLORATION OF CULTURAL DIFFERENCES IN JAPANESE/AMERICAN INTERCULTURAL MARRIAGES

by

MARY ERZEN-TOYOSHIMA

A thesis submitted in partial fulfillment of the requirements for the degree of

\author{
MASTERS IN ARTS \\ in \\ SPEECH COMMUNICATION
}

Portland State University

1986 
TO THE OFFICE OF GRADUATE STUDIES AND RESEARCH:

The members of the committe approve the thesis of Mary Erzen-Toyoshima presented May 15, 1986.

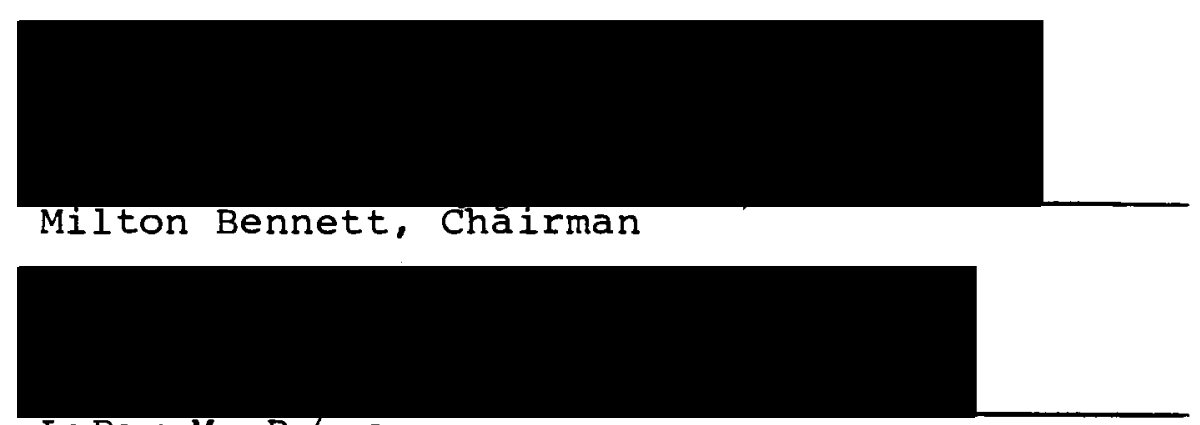

LaRay M. Boxrna

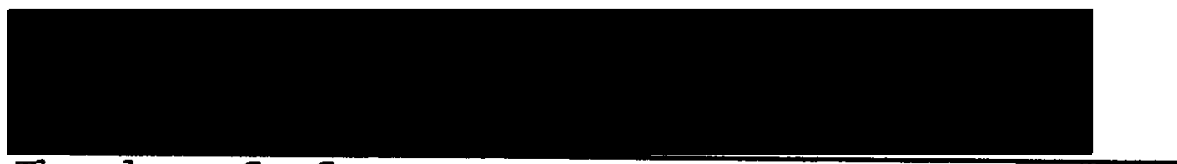

Theodore G. Grove

APPROVED :

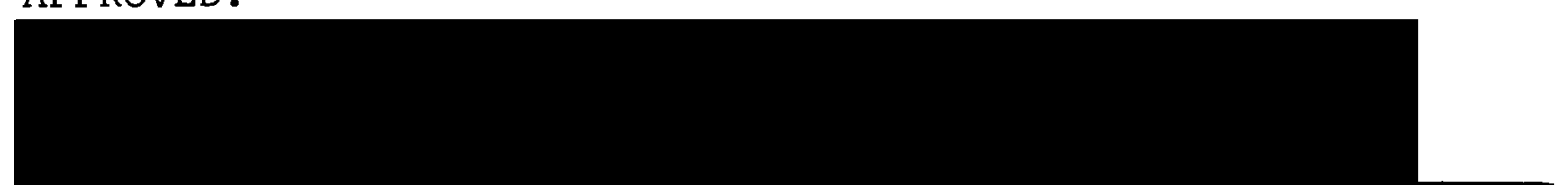

Theodore G. Grove, Chairman, Department of Speech Communication

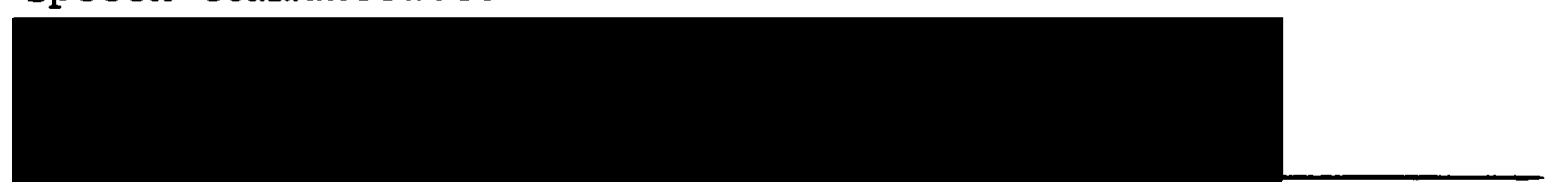

Bernard Ross, Dean of Graduate Studies and Research 


\section{ACKNOWLEDGMENTS}

My personal experience in an intercultural marriage inspired me to write this thesis. However, the guidence and support given to me by my committee members, friends, and family is what enabled me to complete this thesis.

I am especially thankful of my committee, Dr. Bennett, chairman of the committee, whose comments and advice proved invaluable to me, and to LaRay Barna, Dr. Grove, and Maynard Hugo, who all gave me guidence and support.

My special thanks to Ed for his editorial skills and to Jim and Mark for their help with the word processor. I am also indebted to all of the interviewees who shared their time and thoughts with me, and to Kathy and Emiko who encouraged me along the way.

Finally, I wish to express my deepest thanks to my family. I am grateful to my brothers, sisters, father, and expecially my mother for listening patiently and giving words of encouragement. Most of all I want to express my thanks to Morio, who let me pursue my "individualistic goal", and to Amy and Deanna for being patient. 
TABLE OF CONTENTS

PAGE

ACKNOWLEDGEMENTS

CHAPTER

I AN OVERVIEW OF THE STUDY • • . • . . • . 1

Introduction . . . . . . . . . . 1

Purposes of this Study . . . . . . . 2

Justification and Significance . . . 3

Definitions and Assumptions . . . 5

II LITERATURE REVIEW: CULTURAL VALUES • • • 11

Group vs. Individual . . . . . . 12

Dependence vs. Independence . . . . 17

Inequality vs. Equality. . . . . 21

Sex Role Values . . . . . . . 24

III LITERATURE REVIEW: COMMUNICATION STYLE 28

Orientations to Interaction . . . . 29

Code Preference . . . . . . . 36

Interaction Format . . . . . . . 45

IV METHOD AND PROCEDURES . . . . . . . . 52

Procedural overview . . . . . . . 52

The Method . . . . . . . . . 53

Criteria Used in Selection of Subjects 54

The Subjects . . . . . . . . . 56 
CHAPTER

PAGE

The Interview Schedule . . . . .

Time, Location and Interview Session

Data Analysis . . . . . . . . .

Interview Questions . . . . . . .

V RESULTS AND DISCUSSION • • • • • • • •

Cultural Value Differences . . . .

Communication Style Differences . .

VI SUMMARY AND CONCLUSIONS $\quad \cdot$. . • • • •

summary • • • • • • • • • • • •

Effectiveness of Method . . . . .

Iimitations of the study . . . .

Directions for Future Research . •

Applications • • • • • • • . • • 
CHAPTER I

AN OVERVIEW OF THE STUDY

INTRODUCTION

The field of intercultural communication is fairly new, and, unlike other fields, it arose, not as an in-, tellectual endeavor, but to fulfill a need (Hoopes, 1979, p.10). This is a need that is being felt by an increasing number of individuals who are being required to, or desire to, live, work, and communicate with people from different cultures.

The reasons for this growth in intercultural contact are related in part to technological advances. People can easily travel to various parts of the world and advances in communication systems have enabled people to communicate with each other more readily. Economic development has created opportunities for a larger number of people to interact with people of different countries. Historical events, such as war, have also brought people of different cultures together.

As a result of this increase in intercultural contact, we are finding more and more marriages; consequently, there is an increasing need for information regarding the 
special adjustments necessary for a viable intercultural marriage.

Marriage counselors and professionals who deal with the institution of marriage repeatedly emphasize that a good marriage requires good communication. If this is true, it would seem crucial to look at how key cultural differences affect the communication between two people who are striving to mesh together their very different cultural backgrounds.

PURPOSES OF THIS STUDY

Primarily, this study is to check whether the problematic cultural differences reported in the literature regarding long term intercultural encounters between Japanese and Americans, are also reported as being problematic by people in Japanese/American intercultural marriages. In other words, is what is supposed theoretically in some intercultural contexts true in an intercultural marriage context? Secondly, this study will attempt to explore which cultural differences are reported as being more or less problematic. Although the purpose of the study is not to establish causality, some differences that are found will be discussed in terms of variation in couples' cultural awareness and willingness to make adjustments. Thirdly, this study will examine whether there are differences in what the Japanese group and American group perceives as problematic cultural differences. 
These purposes are summarized in the following research questions:

1. To what extent are reports of problematic cultural differences in Japanese/American intercultural marriages consistent with selected problematic cultural differences reported in intercultural literature?

2. How do Japanese and American spouses differ in their perception of problematic cultural differences?

JUSTIFICATION AND SIGNIFICANCE

An exploration of certain cultural differences in terms of how they affect the special relationship which exists in an intercultual marriage is important, not only to couples in intercultural marriages, but to anyone who is communicating with someone from a different cultural background. Because the relationship in an intercultural marriage is long term, requiring a major commitment, it is an ideal relationship to examine, in hopes of determining how an awareness of and adjustment to cultural differences can enrich one's understanding of oneself and the relationship which exists within one's intercultural marriage.

Recognition of cultural differences is the first step to more effective intercultural communication and, consequently, to a better marriage. Without a keen awareness of cultural differences and the role they play in the 
relationship, spouses from different cultural backgrounds as Americans and Japanese, are likely to have considerable conflicts. "Differences therefore, constitute both the essence of cross-cultural learning and the medium of intercultural communication" (Hoopes, 1979, p.33).

The number of intercultural marriages between Japanese nationals and Americans has been steadily increasing in recent years, yet very little has been written about the unique problems, or benefits, these couples in intercultural marriages face (Fontaine and Dorch, 1980, p.330). What little that has been written focuses on the war bride's assimilation into American culture and the discrimination that Japanese-Americans have encountered (Schnepp (1955); Worden (1951); Strauss (1954). Nothing has been written specifically on Japanese/American intercultural marriages of recent years. There is a foreign wives association in Japan which gives support to American women who are married to Japanese men and living in Japan, but there is no support group for those women, nor those men, who are in intercultural marriages and living in the U.S..

I hope then, findings from this study will be helpful to those already in intercultural marriages and to those considering marrying someone from a different cultural background, particularly in relationships where one person is American and the other Japanese. 
DEFINITIONS AND ASSUMPTIONS

Cultural Differences

Hoopes, in Multicultural Education: A Cross cultural Training Approach, categorizes four cultural differences that effect intercultural communication. They are cultural values, customary behaviors, communication style, and patterns of thought (pp.32-33). It is assumed in this study that the categories of cultural values and communication style are sufficient in an exploration of cultural differences. Customary behaviors can be seen as indicative of cultural values and communication style, and patterns of thought underlie both of these.

Another assumption being made about cultural differences is that some differences may be more pertinent to long term relationships than others. Based on research of the literature and personal experience this study will attempt to focus on those value differences and communication style differences which have been shown to be problematic in long term relationships.

Cultural Values

Values have been defined by scholars in a variety of ways (Albert, 1968; Kluckhohn, 1951; Stewart, 1972). However, as Kluckhohn states, all of these scholars agree that values determine whether something is good or bad, right or wrong (Condon and Yousef, 1975, p.51). Values represent what one holds as the ideal, whether it is acutally manifested in behaviors or not. Values do not 
change readily; they endure over long periods of time, giving stability, order, and a sense of predictability to all areas of life (Condon \& Saito, 1974, p.132).

Studies have shown that spouses who share similiar values are more likely to gain satisfaction from their relationship than couples with different values (Schwab and Schwab, 1978 and ort, 1950). It follows that they will also experience greater ease in communicating effectively. Schwab annd Schwab (1978, p.157) report that value differences seem to result in more marital strain and cause more communication problems, and they should be explored to find ways for couples in intercultural marriages to adjust to a shared life. Hoopes (1979) concurs.

...values which are buried beyond awareness in our everyday behavior are not accessible without special effort and are among the fundamental stumbling blocks to effective communication and human relations across cultures (p.29).

Since cultural values differ between cultures, they may be a source of considerable conflict in intercultural encounters, and even more so in intercultural marriages. Values imply "oughtness" (Stewart, 1971, p.12). A thing is valued in a culture because that culture's society believes that it ought to be valued. They believe it is right and good. It is not only that values differ between cultures, but this feeling of oughtness inherent in values is a source of conflict. We are brought up to believe that our value system represents the best and most appropriate way to 
direct our lives (Tseng, McDermott, \& Maretzki, 1977). Although one can learn to accept the validity of other value systems it is very difficult to get away from the feeling that your value system is the best.

Even if one is intellectually aware of a difference in values it is difficult to know how to respond to them emotionally. Furthermore, often we are not aware of our own values until they are challenged by someone with different values. We are not prepared to deal with the conflicts this may generate if we are not certain of the underlying reasons for them. It is particularly important for a spouse in an intercultural marriage to identify his own values as well as the values of his partner in order to improve the quality of the relationship through better understanding (Hoopes, 1979, $\mathrm{p} \cdot 33)$

Although I will attempt to identify which cultural value differences tend to pose problems for couples in intercultural marriages, it must be remembered that values are interrelated and it is for organizational purposes only that I discuss them separately. It must be remembered, too, within a given culture, the entire spectrum of a particular value exists. However, in spite of this diversity, there tends to be a dominant value which is typically held by 
members of the culture (stewart, 1977, p.2). Hoopes (1979) elaborates on this idea when stating that in any society people hold a "preponderance of belief". "Though in each culture the whole range of beliefs may be found, the preponderance differs" (p.27). This study will take as "working hypothesis" the value difference based on those that are preponderant in either Japanese or American cultures.

For puposes of this paper I will refer to the values predominantly found in Japan as Japanese values and those found in America as American values.

However these should be interpreted as referring to those values that seem dominant within that society and which are most often associated with that society (Condon and Yousef, 1975, p.49).

\section{Communication Style}

The manner in which one attempts to communicate is called one's communication style. Samovar and Porter (1985) define communication style as it will be used in this study as follows:

Communication is...a dynamic transactional behavior affecting process in which sources and receivers intentionally code their behavior to produce messages that they transmit through a channel in order to induce or elicit particular attitudes or behaviors $(\mathrm{p} .17)$.

Communication style is reflective of one's cultural background. People from different cultural backgrounds bring to an interaction a communication style which greatly affects the communication process. People unconsciously 
interpret other people's communication based on their own communication style. A lack of awareness of the different cultural norms and social contexts, which are the foundation of communication style, can, therefore, result in misunderstanding (Huruse, 1978, p.2).

How we communicate something is perhaps more important than what we communicate. In marriage, the spouses need to communicate their thoughts and feelings, and if the two of them do this differently, there is a good chance for misunderstanding.

Communication style has been defined and looked at from various perspectives, but, for purposes of this research I will focus on three components of communication style which were suggested by Ramsey and Birk (1983). These are orientations to interactions, code preference, and interaction format.

Although this research talks about Americans as having a particular communication style which is different from Japanese, this categorization process is not meant to be rigid. People are capable of adjusting their communication style to fit the situation and context. The components of communication syle suggested by Ramsey and Birk (1983) are best thought of in the form of a continuum (Ramsey and Birk, 1983, p.239). As was stated in Hoopes" "preponderance of belief" supposition, within the same culture, varying communication style factors are evidenced. Again, there is a preponderance difference, so that a particular 
communication style pattern is usually found to be dominant in a given culture. 
CHAPTER II

\section{LITERATURE REVIEW:}

\section{VALUE DIFFERENCES}

A number of scholars have looked at various dominant values in Japan and/or the U.S. (Cathcart and Cathcart, 1985; Caudill, 1974; Nakane, 1970; Doi, 1973; Stewart, 1972). Although the research on values is relatively vast, there is no one work that the present study could be modeled after. Many of the studies explore only one value, and those that are more extensive examine value differences that are often not as pertinent to long term relations as others. After analyzing the research that has been done, particularly those studies which looked at some value differences in the context of intercultural marriage, (Tseng, 1977; Imamura, 1986; Gewirtz, 1983; Bodger, 1984), I have decided to look at the following four value differences: group vs. individual, dependence vs. independence, inequality vs. equality, and defined sex role values vs. undefined sex role values. I expect these to be the most problematic value differences. The aforementioned expected problematic cultural differences are consistent 
with those reported in the preliminary interviews described in the methods chapter.

Most of the value studies that have been done are an outgrowth of Kluckohn and Strodtbeck's work. Their theory, "Variations in value orientations", is based on the supposition that there are a limited number of universal problems which must be met by all men, but the solutions people hold for these problems differ. The various solutions to these universal problems represent variations in value orientations, and they are present in all societies, but there is a dominant value oreintation in each society, and these dominant values tend to differ between societies (Caudill and Scarr, 1962, p.54).

GROUP VS. INDIVIDUAL

\section{Japanese Orientation}

As mentioned, various studies have been done regarding Japanese values and how they compare with American values. One of the earliest studies was Caudill's and Scarr's (1962) analysis of Japanese value orientations, which was based on Florence Kluckhohn's (1961) theory and method. Caudill concentrates on three of Kluckhohn's value orientations: relational, time, and man-nature. For purposes of this paper I will review only the relational value orientation for it is the most pertinent to intercultural interpersonal relationships. 
The three positions in the relational valueorientation are lineal, collateral, and individualistic. Based on Florence Kluckhohn's analysis, Condon and Yousef describe these relational orientations on a continuum. In the individualistic orientation the "family may be only slightly more than a biological necessity", in a collateral orientation the "family identification is strong, but membership is much more limited in generation and number of relations", in the lineal orientation the family includes a very large extended family (p.74). Caudill and scarr (1962) define these relational orientations slightly differently. Lineal realtions are those which emphasize the relationship between parent and child. An example of this lineal relationship in a family would be the passing of authority from from father to eldest son. Collateral relations are those found among siblings. Finally, individualism is based on the uniqueness of each person. Each person makes their own decisions independent from others (41).

Caudill and Scarr's study (1962) found the dominant relational value orientation in Japan to be collateral, rather than the "traditional" lineal value orientation. Caudill suggests that the unpopulariaty of the lineal orientation may be due to a commitment to working together as a family rather than following intrafamily lineal authority. Also, it was found that the younger generation tended to reject lineality when it was presented in an obvious way to them and chose collaterality. Therefore, the 
collateral dominance could be attributed in part to the younger generations rejection of "traditional values" (Caudill and Scarr, 1974, p.84). In both the lineal and collateral orientation, however, there is an overriding concern for members in one's own familiy group. Caudill's study confirms that Japanese tend to value the group. They are more concerned with relations in their family group than they are with their individual selves.

Furthermore, the Japanese' obligation towards family members is expected. Parents feel an obligation to care for their children even after they are mature adults. Likewise, the eldest son is obligated to take care of his parents in their old age. The Japanese emphasize extended family obligations (Imamura, 1986, p.12).

Chie Nakane (197ø) discusses the Japanese group consciousness in her book Japanese Society. She discusses Japanese "ie"-- the family, or household-- as being the basis for group consciousness in Japan. It is in these first relationships within the family that one learns the values of belonging to a group. The whole emphasis is on the integration of family members into one unit. Through this socialization process one learns that his primary goal is the welfare of the group. "It is the group that should grow, prosper, survive, and it is the group from which the individual obtains support, identity, and pride" (Barnlund, 1975,p.162). Pursuit of individual goals is seen as hindering the harmony of the group. Individual fulfillment 
of self is achieved through finding and maintaning one's place within the group, (Cathcart \& Cathcart, 1985, p.191) and there is no conflict over feeling that individual pursuits or rights are given up for the group. (Doi, 1973, p. 135)

There is a Japanese word, "dotaishi", which, when used in reference to a married couple, means 'husband and wife are one'. They make up a unit, and it is this unit that is important, not the individuals that form the unit. Later, when children are born into the family the mother and children form the central core of the family to which the husband attaches himself. The husband is concerned with the family as a whole, rather than his with wife and children as individuals (Nakane, 197ø, p.127).

\section{American orientation}

Caudill's study (1962) indicated that the Americans were more individualistic in their family relations. They relied on themselves, rather than their families.

Basically most Americans feel that each adult member in the family is responsible for his own life. Each individual in the family should be as self-reliant, and free from family expectations and obligations as possible. of course, there is a sense of cooperation among family members, but it arises out of individual choice and desire (Condon, 1984, p.9). 
American society emphasizes the "self". Americans are brought up to value self-sufficiency and independence and are constantly asking themselves "who am I?", not in relation to someone else, but separate from others. In America, individual well being and success, rather than group goals, are of prime importance.

Intercultural Marriage Application

The cultural difference of group versus individual in one's relational orientation to the family is important in an intercultural marriage because it affects how one will go about doing a great many tasks. (Condon and Yousef, 1975, p.75). For example, an American who has an individualistic orientation toward the family may prefer to go to an outside source for help, whether it be counseling for marital problems or a bank for a loan. A Japanese, following a collateral orientation would more likely ask for help from someone in the family. There is potential conflict when two people, having the same objective, differ on the best way to reach that objective. Problems arise because one person is using the "self" as a frame of reference from which to act, whereas the other person may use his family as a frame of reference.

The group and individual value difference can even be seen at work in one's reason for marrying. In Japan one marries to start a family, and even for those women who would like to pursue careers, or not have children, there is 
sufficient social pressure that, eventually in most cases, these women conform to getting married and having children. Americans, on the other hand, marry in hopes of attaining individual happiness and fulfillment. Problems, of course, may arise if spouses have different expectations gcing into the marriage.

This basic value difference can be a point of conflict for many American and Japanese in intercultural marriages. Americans see their attempt to achieve an individual goal as thier right, they see it as something good. The Japanese spouse, however, sees this action as a selfish pursuit of individual happiness (Trommsodorff, 1976, p.339). In Japan "notions of individual happiness are often subordinate to the well-beirg of the family unit (Gewirtz, 1983, p.25).

DEPENDENCE VS. INDEPENDENCE

Japanese Orientation

In accordance with the Japanese value of the group is the value of interdependence. The Japanese word "amaeru" is used throughout much of the literature for the concept of interdependence. "Amaeru" is difficult to translate accurately, but it comes close to the idea of "sweet dependency" (Gewritz, 1983, p.25) which occurs between people in a close relationship such as mother-child or husband-wife. To be able to "amae" is to presume upon another's love knowing that your actions will be accepted (Doi, 1973). 
Willam Caudill and Weinstein (1969) have done comparative research on the child-rearing practices in Japan and America, and have found that the practices in Japan foster dependence. The Japanese are brought up to feel that being dependent on each other is good. Dependence is fostered from childhood on into adult life. Children are not encouraged to be self-reliant, but rather, are brought up to depend on their parents. The Japanese children are rarely separated from their mother, which encourages not only a strong physical dependence but also, a strong emotional dependence. Japanese infants are usually fed on demand, they are often strapped to their mothers back, and they most often sleep with their parents in the same bed or at least in the same room. In Japan dependency is considered necessary for building warm human relationships. The infant in Japan is thought of more as a seperate biological organism, who needs to be drawn into increasingly interdependent relations with others in order to develop (Caudill \& Weinstein, 1969 p.42).

American Orientation

Americans who value individualism also value mutual independence. Caudill and Weinstien's 1969 study found that the child rearing practices in America fostered independence. In America the infant is regarded as a dependent biological organism who needs to become increasingly independent of others in order to develop 
(Caudill and Weinstein, 1969, p.42). American infants, are often put on a feeding schedule, periodically left with babysitters, and almost always sleep separate frcm their parents. American children learn from the time they are infants to deal with occasionally being separated from their mothers, encouraging them to become emotionally and physically independent. In America dependency is thought of as a restrictive element. It doesn't allow one to reach one's full potential. Therefore, dependency is discouraged and independence or self-reliancy is emphasized. (Cathcart and Cathcart, 1985, p.192)

Intercultural Marriage Application

According to the above contrasts this value difference between dependent ard independent orientatiors could conceivably cause difficulties in an intercultural marriage. The Japanese partner will likely expect to be able to "amae" to his or her partner. If that partner is American there may be problems in the way this action of "amae" is interpreted. As was indicated in the Japanese orientation section, the Japanese feel that dependency is the basis for warm and loving relationships. To the Japanese this ability to depend on one's spouse signifies a closeness and kind of love. The American may see it as burdensome and childish.

"A husband may act in a childish way as a sign
that he wishes his wife's indulgence. A Western
wife often dces not appreciate this "amae" and 
resents her husband's requests to draw his bath or cook his late night meals. She does not bask in its sweetness like her Japanese counterpart" (Gewirtz, 1983, p.25).

An American may interpret one's need to express a feeling of dependency as a sign of a selfish refusal or weak inability to accept one's own responsibilities (Naotsuka and Sakamoto, 1981 p.17). An American may also feel irritated at having been asked to do something for his or her spouse which the spouse could have done independently. This is not to say that Americans do not do things for each other, however, there is a sense among Americans of selfresponsibility and there is a certain amount of pride taken in being self-reliant.

For the Japanese woman it is her main responsibility to provide her husband with a place in which he can "amaeru"a place where he can indulge in the comfort of being taken care of. The Japanese woman feels a sense of pride in taking care of her husband and children. She achieves a feeling of personal self-worth and comfort from a feeling that she has done a good job as a wife and mother. (Brannen and Ramsey, 1979 p. 479) Perhaps what an American woman feels when she complies with her husband's desire to "amaeru" is a "loss of self" for she must deny herself much in order to take care of the total physical and emotional needs of her husband. She must never allow her own needs to interfere with her husband's ability to "amae".(Brannen and Ramsey, 1979) 
The polarity of the Japanese and American concept of self and group, and, concurrently, their value of independence and dependence, requires those invloved in an intercultural marriage to be aware of these value differences in order to help cross communication barriers (Cathcart and Cathcart, 1985, p.190).

INEQUALITY VS. EQUALITY

Japanese Orientation

In conjuction with the Japanese value of the group is the belief that inequality is the natural order. "There is no place for the concept of the individual as an independent entity equal to other individuals" (Kawashima, 1975, p. 275). The Japanese live in a society in which everyone has a certain position relative to the other people in their group. Nakane (197ø) discusses this characteristic of Japanese society in terms of its vertical or hierarchical nature. This "vertical society" is evidenced in a number of ways. The Japanese language is the epitome of the hierarchical nature of Japan. One can not refer to another person without indicating his relative position to that person. For example, at work or school you are either a "kohai" (one's junior), "dohai" or "dokyusei" (one's equal), or a "sempai" (one's senior), depending on the time you entered relative to the others. Family relations are normally referred to according to age. One is either an 
elder or younger sibling. The choice of words and verb forms defines your position relative to the person or persons you are addressing. The language you use also indicates who your superiors and inferiors are. "The superior person (by virtue of status) provides paternalistic benevolance while the inferior membership in the relationship shows dedication and sacrifice" (Buck, 1984, p. 285). In a husband-wife relationship the husband is normally considered to be the superior who provides his family with finacial security. The wife, then, is the inferior who dedicates herself to her husband and children. She devotes her complete self to her family.

American Orientation

Although there are many examples where equality between racial groups or the sexes is not found, Americans tend to think of equality as the ideal.

"Running through the Americans social relationships with others is the theme of equality... Interpersonal relations are typically horizontal, conducted between presumed equals." (Stewart, 1972 , p.46)

Naotsuka and Sakamoto's (1981) study revealed the American dislike for signs of inequality in relationships. In response to the Japanese way of deferring to others out of politeness an American said "They should be equal, not inferior" (p.40). 
Intercultural Marriage Application

This value of inequality as evidenced in Japan's hierachical society may be problematic for an intercultural couple, especially in the case where the husband is Japanese and the wife is American. It may be difficult for an American wife to treat her husband as a superior. An American woman feels and wants to be treated as though she were equal to her husband and would want to participate in a relationship as such. On the other hand, in the traditional Japanese family the husband is master of the house. In fact, the word for husband, "shujin", means master, boss, ruler, etc. "A wife must subordinate her will to the authority of her husband". (Haglund, 1984, p. 71) This act of subordiantion or obedience may be very difficult for an American wife. In fact, Barnlund (1975) states that the emotions of respect and deference are the most painful emotions Americans experience because of the emphasis on equality as the ideal. (p.164) An example of this would be a Japanese husband's request that his wife dress a certain way and have a particular hair style. The American wife may feel that she shouldn't have to follow her husband's directives regarding her personal appearance. She should not have to subordinate her will to the authority of her husband if she is an equal. She would also expect to be able to discuss issues together, rather than merely accept her husband's wishes. 
Ruth Benedict (1946) depicts the potential conflict this value difference of equality/inequality has in a relationship between an American and a Japanese in the following:

Any attempt to understand the Japanese must begin with their version of what it means to "take one's proper station." Their reliance upon order and hierachy and our faith in freedom and equality are poles apart (p.43).

SEX ROLE VALUES

Japanese Orientation

The roles of men and women, husbands and wives, are clearly defined in Japan. Furthermore, these roles are valued as being the proper roles. A typical definition of a "good wife" is "good cook, child bearer and raiser, minds her husband while taking care of him without complaining" (Brannen and Ramsey, $1979 \mathrm{p} .475$ ). Japanese women are almost totally responsible for the household and the children's upbringing. On the other hand, Japanese men are the breadwinners. "A good husband is one who is healthy and absent" (Gewirtz, p.25, 1983). He goes to work everyday, returning at night, having earned a days wages. Very rarely are these roles reversed in Japan. There is no term in Japanese for "househusband", due to the fact that seldom is a man responsible for the housekeeping or child care. Likewise, although there are an increasing number of professional women in Japan, they are still not accepted or valued as they are in the U.S.. 
American Orientation

The sex roles in the U.S. tend to be less defined than those in Japan. There is a wide range of individual choice or opportunities with regards to roles. Unlike in Japan, there are a number of professional women who share various duties with their husbands that were previously thought of as women's duties. There are also more and more men now who enjoy their new roles of housekeeper and child care giver. The meshing of roles has become the accepted norm in the United States.

Intercultural Marriage Application

Role expectations and the actual roles played by spouses can be the cause of difficulties in a marriage, particularly in an intercultural marriage where there is more likelihocd that the role definitions and expectations for husband and wife will differ.

An American who expects freedom to choose his/her roles may encounter difficulties if married to a Japanese who has rigid role expectations and dislikes deviation from this Japanese norm. Tension in the relationship may result if, for example, an American woman who is very career corscious is asked by her husband to stop working and stay home to take care of him and the house. This is the role that he expects a wife to play, ard he may have difficulty understanding why his wife would be reluctant to give up her job in order to fulfill this very important role. The role 
of wife in the U.S. ,however, does not receive the same recognition it does in Japan. An American woman tends to need to develop other areas in her life in order to receive personal satisfaction and recognition from others.

The Japanese housewife, then, her territory and responsibility clearly defined, takes pride in her home ard in her family. She enjoys social approval of her emotional stength in being the central integrating force of the family. Her status as a wife may be low by American standards, but her status as a mother is probably higher and certainly her security is geater (Vogel, 1978, p.41).

A person expects certain roles for himself and certain roles for his spouse, but because individuals often have more than one role to fill-- for example, a man may be husband, father, and businessman-- one of these roles may take precedence over the others. The role then, that a person's spouse expected him to fill may go unfulfilled. To continue with this example, a man's role of husband may not be filled as the wife had expected, or wanted, because that man's role as businessman took precedence (Ort, 1950, p.692). Likewise, at times a woman's role as wife may take second place to her role as a professional, and this may cause friction within the marriage if the husband has expected the woman's role of wife to always come first. He may allow her to continue her outside activities only if they do not interfere with her wifely duties. Potential conflicts arise over the question of priorities. A professional teacher may not think she should be expected to put off doing her lesson plans until after she has served 
her husband's late night meal, just as a Japanese man may not understand why his wife becomes upset that he must go out every night with his work collegues. However, "as actual roles come to differ from anticipated ones, accomodation takes place or the marriage dissolves" ( Imamura, 1985, p.15). 
Communication style, or one's total communicative behavior, plays a vital role in the interaction between two people. In fact, it determines what meaning will be interpreted from the message, whether that be an intended message or not. Communication style becomes even more crucial when the interaction involves two people from different cultural backgrounds, and it is especially important in an intercultural marriage to be aware of the communication style differences and how they are affecting the interaction between oneself and one's spouse.

Comparative studies of American and Japanese communication styles have been done by various scholars. Barnlund's (1975) study of the communication style differences between Americans and Japanese looked at preferred topics and form of interaction. It also looked at which channels-- vocal, verbal, physical-- were used for conveying information and how each of these forms compared in factual or emotional content. (Barnlund, 1975 p. 15) Condon (1984) examines what he feels are some key issues in the communication process between Japanese and Americans. He looks at such issues as 
verbalization versus silence, turn taking, and directness versus indirectness (Condon, $1984 \mathrm{pp} \cdot 39-44$ ). Huruse (1978) examined verbal and nonverbal characteristics, as well as the differing thought patterns of Japanese and Americans. Ramsey and Birk (1983) reviewed the following three elements of communication style: orientations to interactions, code preference, and interaction format. I will explore these same three areas of communication style and look at differences which may be problematic in an intercultural marriage.

ORIENTATIONS TO INTERACTIONS

$$
\text { U.S.A. }
$$

JAPAN

Locus of Self: Individualistic Interpersonal View of Reality: Objective Subjective Orientations to interaction can be viewed as a person's cultural values and assumptions regarding interpersonal interactions.

INDIVIDUALISTIC VS. INTERPERSONAL

Included in the orientation to interaction is the "locus of self" which for the Americans is individualistic and for the Japanese interpersonal. These differing orientations are reflected in the Japanese' and American's particular communication styles (Ramsey \& Birk, 1983, p.24ø) 
Japanese Orientation

Japanese indentify themselves with a work group, family, college friends, etc. It is very important to belong. Barnlund (1975) indicates how this Japanese group orientation effects their communication style in the following :

The orientation is collective rather than individual. Much of the communication behavior, therefore, is focused not on securing attention or advantage for himself, but to sacrificing self to secure advantage and prestige for the group (pp.162163).

Kunihiro's (1976) research also indicates that the interpersonal orientation of the Japanese is reflected in their particular communication style. In Japanese "there is a sense of leisurely throwing a ball back and forth and observing each others response" (p.62). Kunihiro (1975) states that the Japanese must consider how they are affecting the group when they express their thoughts and therefore, are reluctant to speak out too much for they may isolate themselves from the group (p.265).

The most important thing is to pay as much attention as possible to the adjustment of human relations, to prevent quarreling with others in one's group and to avoid causing any kind of criticism" (Kunihiro, 1975, p.265).

American Orientation

Americans are brought up to believe that it is important to "discover oneself". This discovery of who we are is aided by sharing our different experiences, 
abilities, and opinions with others. Being different is good; it defines our individuality. This individualistic orientation of Americans becomes apparent in their communication style.

"... In the languages of the West, logic and reason are continuosly tossed between speaker and listener as if one's identity were constantly being questioned, and throughout there is a sense of reinforcing each other's independence" (Kunihiro, 1976, p.62).

\section{Intercultural Marriage Application}

This Japanese concern for the human relations in one's group over the individual self could be problematic in an intercultural marriage. For example, Americans are more likely to assert their opinions and argue back if challenged, or at least defend their opinions, while Japanese will be less concerned with their individual opinions and more concerned with conforming to the group. "The average Japanese concerns himself more with how the group thinks or feels than with how he thinks or feels" (Golden, Dec.5(B3), 1982). In a husband-wife relationship there may be problems if the American feels the necessity for both persons in the marriage to assert their opinions and or feelings, even when they are in disagreement. For example, a Japanese woman who Bodger (1984) interviewed, said learning to express her opinions was taking a lot of effort. She feels reluctant to express her feelings about her American husband's music performance. Her husband revealed his disatisfaction with his wife's inablility to 
express opinions in the following "I'd almost rather hear a forthright 'I don't like it' or something" (Bodger, 1984 p.356). In contrast, the Japanese feels it is more important to refrain from expressing personal opinions, and certainly withhold contrary feelings or opinions. One complaint often heard from Japanese men about a woman who feels strongly about her right to speak her mind is "urasai", meaning a noisy bother. A good wife according to many Japanese men should not complain, nag, whine, or differ with his opinion. "A good wife is a quiet wife" (Brannen and Ramsey, 1979, p.474). Supression of self expression comes to influence the relationship in both cases-- Japanese husband and American wife or American husband and Japanese wife.

OBJECTIVE VS. SUBJECTIVE VIEW OF REALITY

Those individuals holding an objective view of reality are inclined towards a belief in cause and effect relationships, and linear determinism (Ramsey and Birk, 1983, p.30). Those holding a subjective view of reality are more inclined to use social relations as the means to an end (Lebra, 1976, p.4).

Japanese Orientation

Japanese tend to have a subjective view of reality. they do not follow the Western linear type of logic. They are more likely to come to a conclusion from a feeling they have about the situation. The cognitive and affective 
processes work as one, allowing the Japanese to come to some decision or conclusion based upon their perception or feeling.

Mushakoji (1976) describes the differences between American and Japanese views of reality as "erabi" and "awase" respectively. The "awase" view is one of adjusting to the environment. An "awase" person thinks of things falling on a continuum and the importance of adjusting to this continuum of change.

This distinction between an objective and subjective view of reality was described by Roichi Okabe (1983), as realism and idealism. "Japanese thinking is predominatly that of idealism. It puts greater stress on subjective ideas than on objective facts" (Okabe, 1983, p.28). Japanese are more concerned with the "human relation reality" (Ramsey and Birk, 1983, p.240) and use these relations when making a decision or in coming to some sort of conclusion. Their actions are influenced more by the social relationhips involved and are not as easily explainable; it "depends" (Lebra, 1976, p.8).

American orientation

Americans tend to have an objective view of reality. This is consistant with Mushakoji's (1976) description of Americans as holding an "erabi" view of reality. "The erabi view is that ideally man can freely manipulate his environment for his own purposes" (Mushakoji, 1976, p.40). 
In other words, an "erabi" person has an objective, creates a plan to achieve that objective, and then proceeds to follow that plan. The logic inherent in this "erabi" view is one of dichotomies, whereby a choice is made between two opposites. Something is either right or wrong, true or false etc.

According to Okabe (1983), Americans' view of reality is based on realism. Realism is factual. It puts its focus on objective facts. The communication style of Americans reflects their values of objectivity, specificity, and precision. "Americans present their argument with as much detailed (analytical) and factual (objective) support as possible." (Tamura, 1982, p.28) Americans come to conclusions or make decisions based on a premise that has been analyzed free from subjective elements; Their consequent actions and statements are clearly and simply explainable.

\section{Intercultural Marriage Application}

The basic difference in the Japanese and American orientation to interaction can ke problematic in an intercultural marriage. An American who is basically a self oriented being, acting from an objective view of reality, will meet with some conflict when interacting with a Japanese who is group oriented and holds a subjective view of reality. The mere act of planning for a vacation may cause conflicts. First of all an American wants to know if 
the family or couple can go on a vacation or not. Secondly, the American wants to set a specific time, plan the route and stopovers, and take care of all the other details that go into planning a vacation. The Japanese may find the American's attempt to make these arrangements with him or her overwhelming and pushy. The Japanese may cooperate, but the agreements will be tentative ones. In other words, the door must be left open for any unexpected changes and then the freedom to make the adjustment. Americans have commented that their Japanese spouses will say something like "Don't be so pushy". The Americans cannot understand why their spouses have interpreted their actions as being pushy or agressive and in fact they may view the Japanese as indecisive.

There are other instances where the different orientations to reality may cause problems. An American may aggravate his or her spouse with an objective statement regarding someone, particularly if that statement has some emotional impact on the relationship of those involved. For example, Japanese men have often said that their American wives would make a statement, regarding a member present at a social gathering of business collegues, which was upsetting to him because of how he thought that statement affected his relationship with those present. Problems may arise because Americans, unlike Japanese, tend to be relatively objective and unemotional in the area of human relations (Ramsey and Birk, 1983). 
CODE PREFERENCE

$$
\text { U.S.A. }
$$

JAPAN

Emphasis on the Verbal

Emphasis on the nonverbal

The second component of communication style, code preference, includes verbal ard nonverbal communication. Verbal communication is used among all people, but the extent of its use differs between cultures. Americans are more inclined to emphasize the verbal, where as Japanese emphasize the nonverbal.

VERBAL COMMUNICATION

Japanese and American Orientations

Verbal communication, both in the encoding and decoding process can be problematic in intercultural communication. When one person is using the native language of the other person, misunderstandings can result from the different interpretations each hold for a particular word or phrase. For example, the simple word "yes", which to an American is used to express ageement, to a Japanese is often used to mean "I hear you". (Ramsey, 1983 p.23) Also, many words do not have equivalents in the other language. For example, the word "amaeru" which was referred to earlier as "sweet dependence" is not really translatable, and yet it is very important in talking about relationships in Japan. Another example is the English word "privacy" which has no real equivalent in Japanese. In addition to lack of equivalency there are some words that actually hold opposite meanings. 
Ruth Benedict (1946) points out this phenomenon with the word "sincerity" as an example. In English it is the value of frank and honest expression of one's inner thoughts, but in Japanese this kind of expression is regarded as insincere.

The fact that words in the two languages which, according to the dictionary ought to be equivalent are often even antonymous represents a larger, major problem point in U.S.-Japanese communication (Kunihiro, 1976 p.265).

Language, thus, poses problems because of the different ways language is used and interpreted.

NONVERBAL COMMUNICATION

Language, however, is probably not as problematic as nonverbal communication is, especially between married couples. Probably, they more readily learn to adjust to language differences than to nonverbal communication differences because the nonverbal is not so apparent. Nonverbal means are used more often to express one's feelings and emotions, which are particularly important in a married couples relationship.

\section{Japanese Orientation}

The Japanese tend to emphasize nonverbal communication rather than the verbal. "To the Japanese, language is "a" means of communication, whereas to the people of many other cultures it is "the" means (Kunihiro, 1976, p.56). 
In relation to this idea of code preference is Hall's (1976) analysis of Japanese and American communication as being high and low context respectively.

A high context (HC) communication or message is one in which most of the information is either in the physical context or internalized in the person, while very little is in the coded, explicit, transmitted part of the message.A low-context(LC) communication is just the opposite; ie, the mass of the information is vested in the explicit code (Hall, 1976 p.91).

Japanese, who tend to be from a high context culture, use only minimal verbal language in conveying a message. They expect the persons they are talking with to already have a certain amount of preprogrammed information and the ablity to pick up additional information from the setting. Japanese value the person who "can hear one and understand ten" (Condon, 1976). The homogeneity of Japan has allowed for the development of an intuitive sense and the ability to rely on nonverbal channels to communicate (Lebra, 1976, p.46).

Similar to Hall's analysis of Japanese and American communication as being low context and high context respectively, is Bernstein's (1964) analysis of "elaborated" and "restricted" linguistic codes. A person oriented toward using an elaborate code will verbally express his intentions and experiences in explicit terms. A person oriented towards a restricted ccde would not verbally expound on their intent. The participants are dependent on a basis of shared assumptions (Bernstein, 1964 p.57). "In restricted 
codes, to varying degrees, the extraverbal channels become objects of special perceptual activity; in elaborated codes it is the verbal channel." (Bernstein, 1964, p.63) Japanese tend to use restricted verbal codes.

Lack of awareness of the extraverbal/nonverbal channels used by Japanese may create communication problems. For example, the use of silence conveys a great deal of meaning in Japanese (Lebra, 1976, p.46). An American man listening to a negotiation in Japanese felt pleased that he had understood what had been said at the meeting. However, in a later discussion with a Japanese who was also present at the negotiations he learned that in fact he did understand what had been said, but he failed to understand what the silences had meant and, thus, mistook an unsuccessful negotiation for a sucessful one. Silence is not merely a void left to be filled. It has definite meanings as illustrated by the above example. It can also be a sign of respect to the person who has spoken or a means of unifying speaker and listener (Condon, 1984, p.40).

Doi (1973) found that the Japanese use the silent breaks in their conversations to feel out one another to achieve a shared mood-- a mutual feeling of interdependence. Doi states that the "verbal communication is something that accompanies nonverbal communication and not the other way around" (Doi, 1973, p.181). 
Another nonverbal means of communication widely used by Japanese is the use of objects. (Ramsey, 1983 p.247) Japanese often use objects to convey their feelings. For example, an abrupt change for the worse in the food you are served can signal that something is amiss in the relationship. This can also work in reverse. An American's unintentional nonverbal behavoir may be interpreted by a Japanese according to what that behavior would mean among Japanese.

Form is also an important element of nonverbal communication for the Japanese. Form refers to the way a message or task is carried out, as compared to what that message or task is.

American orientation

Americans view language as the means of communication rather than as a means (Kunihiro, 1976, p.56). This emphasis on the verbal language can be seen from the interaction between mother and infant. American mothers engage in much more verbal interaction with their infants than Japanese mothers. Infants are encouraged from very early on to view communication with others in terms of verbal communication (Caudill and Weinstien, 1969, p.42).

Americans are representative of a high context culture (Hall, 1976). Americans use more verbal lanaguage to facilitate understanding since they assume the other person does not have a lot of preprogrammed information, and can 
not simply just pick it up from the setting.

Americans, who tend to use an "elaborated code", find it necessary to verbalize extensively in order to feel comfortable that they have made themselves understood. In cultures where use of an elaborated code is the norm, the listener is dependent on the "verbal elaboration of meaning". (Bernstein, 1964)

The important nonverbal channels found among Japanese have very different significance among Americans. For example, "More often than not in Western culture silence is viewed more negatively than positively" (Johannesen, 1974, p.27). Form, also, is not considered to be as important as it is in Japan. The emphasis on how something is down is sometimes seen as insignificant to what is done. (Condon, 1984, p.17).

\section{Intercultural Marriage Application}

This difference in code preference can be an obstacle for effective communication in an intercultural marriage. I have often heard Americans say "If she/he only had told me... there wouldn't have been any problem". The Japanese person assumes, because they share so many of their daily activities together, that they don't have to verbalize everything; their spouse should understand without it being said. Although the Americans might be able to appreciate the subtle linguistic differences, they may not notice the subtle, but important, nonverbal differences. The Japanese 
may not realize the necessity of verbalizing their thoughts and feeligs in order to facilitate understanding between themselves and their American spouses.

Problems arise over the difference in emphasis, and use, of both the verbal and nonverbal codes of communication. Even the use, or non use of the simple phrase "I love you" can cause problems. Americans may complain that their spouse doesn't say 'I love you' since they need that verbal reassurance. On the contrary, a Japanese may find it irritating to be told "I love you" by one's spouse since it is obvious if you are married and need not be expressed. "It's rare for the Japanese to say "I love you" once married- the marriage itself is considered proof enough".(Bodger,1984 p.356) This also relates back to the group concept. Once you are married you become one with your spouse; she/he is an extention of you. Therefore, one need not say one loves oneself.

Problems may arise when someone from a high context culture communicates with someone from a low context culture because the necessary programming is lacking in the low context person, causing a breakdown in the communication. People from high context cultures expect more from those they are interacting with. If they are talking about something, they will expect the listener to understand what is being said, and won't want to explain in detail. Often times they will expect the other person to know how they are feeling, or that something is bothering 
them, and to respond accordingly without them having to say anything. In high context cultures the context provides all the necessary information for an appropriate response. This can pose problems in an intercultural marriage, for Japanese expect their spouses to anticipate feelings and needs, and act accordingly without any verbal exchange, or the Japanese may allude to a need or desire by a vague statement. For example, the most basic of needs-- food, can become a difficult area when a high context person is interacting with a low context person. A Japanese husband may expect his wife to proceed to prepare a meal based on the following statement "I only had a small bowl of noodles for dinner", and would be irritated or frustrated if his wife failed to respond to this and did not prepare him something to eat. An American, however, would normally require more explanation and, most likely, an actual verbal request before she proceeded to prepare a meal. Furthermore, the Japanese husband may expect a certain kind of food to be made depending on the situation and will expect his wife to know this without him having to specify what he wants.

Problems may also arise when a low context person is trying to communicate with a high context person. For example, the low context person may go into an elaborate detailed explanation of why he/she did something, only to find her spouse bored at having to listen to things that could be inferred from the context. The Japanese rely on 
their intuitive sense, rather than on explicit expression to infer meaning.

In an intercultural marriage the different ways silence are used may be problematic. A Japanese spouse may use silence as a means of expressing disagreement or dissatisfaction and may see their spouse's failure to understand the meaning of the silence as insensitivity.

Again, Japanese often use objects as a nonverbal means of communicationg. For example, a Japanese husband was said to have asked his wife, "Why are you being so cold to me"?, after he had been prepared what he felt were unsatisfactory meals. The fact was, however, that the wife was just not feeling very well.

Form is another widely used nonverbal channel used by Japanese. A Japanese may become irritated if his or her spouse had agreed to do something, but had done so in a reluctant manner. They tend to focus on the reluctant tone conveyed, rather than on the fact that an agreement was reached. In regard to tasks, it is not so much whether the task was completed but, how it was completed. 
INTERACTION FORMAT

$$
\text { U.S.A. }
$$

Persuasive

Quantitative

Pragmatic
JAPAN

Harmonizing

Holistic

Process oriented

PERSUASIVE VS. HARMONIZING

The objective view of reality held by Americans corresponds to their persuasive communication style. Americans feel that if you logically and objectively lay out the facts, detailing precisely the cause and effect relationships, the other party will have no problem seeing it your way. The Japanese have a harmonizing style of communication. They do not persuade, but rather "create a softley blurred buffer-zone designed to foster mutual sympathy." (Naotsuka and Sakamoto, 1981, p.175)

\section{Japanese Orientation}

Japanese prefer to harmonize. The Japanese hold a subjective view of reality, and thus, are more concerned with allowing for the other person to feel as a contributer to the outcome. The Japanese think in terms of "I start my sentence" and "you finish it", rather than "I finish my sentence and then you say yours" (Ramsey and Birk, 1983, p.251). In fact, the very structure of Japanese, where the affirmative and negative forms of the verb fall at the end of the sentence allow for one to observe the other persons response before expressing one way or another (Doi in 
Condon and saito, 1974, p.23). In this way, one can avoid any disagreement or soften one's opinion in order to maintain a harmonious relationship. "To preserve harmonious relations becomes the overriding concern in interpersonal encounters..."(Kunihiro, 1976, p.6Ø). American orientation

Americans tend to want to persuade. Americans seek to convince the other party to agree with their point of view. They attempt, in a unilateral fashion to persuade the other person into thinking the same way they do. This persuasive style goes back to the objective reality point of view that Americans hold. If we show others the facts in a lcgical fashion, Americans will be sure to see our way of looking at things.

Intercultural Marriage Application

The difference in the interaction format may be problematic in an intercultural marriage. An American may not want to harmonize if it means forsaking integrity. For example, An American may find it difficult to apologize for something that he or she may have done just because it will maintain harmony. "I'm not going to say I'm sorry, if I didn't do anything wrong". It seems almost dishonest to say we're sorry when we aren't (Ramsey, 1983, p.235) . Japanese, however, are more concerned with smoothing relationships and maintaining harmony than they are with individual integrity and honesty. It doesn't matter whose fault it is, what 
matters is that harmony is maintained. Americans tend to use logic and reason to convince the other person that they were correct in doing or saying something, but the Japanese make no attempt to persuade the other person into thinking one way or another. Americans may wish to explain their actions only to be told that their spouse does not want to hear it. This can be very frustrating for both sides. It is interesting to note that many articles concerning intracultural marriage stress the importance of a couple's ability to confront differences rather than avoid them for the sake of harmony. The following is an example of this emphais on confronting differences to improve the relationship. An example of a culturally biased observation is a statement made by Hawkins (1984) in a typical U.S.A. marriage advice column.

A husband and a wife tend to develop a style of communication...If this style enables them to express attitudes and feelings frankly and to face, rather than evade differences of opinion, so much the better for the marriage (Hawkins, 1984, p.13).

QUANTITATIVE VS. HOLISTIC APPROACH

Americans use quantification to communicate their feelings and experiences. Quantification facilitates "expedient logical action" (Ramsey and Birk, 1983, p. 252). Japanese, rather, tend not to quantify. The Japanese are more likely to use common sense in place of quantification (p. 253). 
Japanese Orientation

Japanese use a synthetic or holistic approach. They try to grasp things in their totality. Rather than analyzing and disecting into parts, they synthesize into a unified whole. (Okabe, 1981, p.28)

American Orientation

Americans use a quantitative approach in communiction. Americans analyze, and break things down into their parts, which they then quantify in order to understand them more completely. They focus on the parts rather than the whole.

Intercultural Marriage Application

The difference between the Japanese holistic approach and the American quantitative approach may pose problems for an intercultural couple engaged in a discussion. An American tends to begin the discussion with a presentation of facts and figures from which a conculsion is drawn. The Japanese, however, either presents ideas in an episodic fashion leaving the conclusions unstated, or presents ideas without supportive data (Kunihiro, 1975, 263). A clash or misunderstanding may result from these different styles. An Americh may respond with "so what!" or "What difference does that make!" to a Japanese who merely stated maxims and axioms without any supportive data. An American needs those figures and facts in order to draw conclusions. 
Americans tend to use quantitative expressions when trying to convey a feeling about how well the relationship is going. For example they might imply that things are not going well by such statements as, "We've only gone out together once this month", or "You have come home late three nights this week". Japanese, however, would probably give some nonverbal cue conveying a general feeling that the relationship was not going well. Japanese base their evaluation on feelings rather than on numbers (Birk and Ramsey, 1983, p.252). They do not need to quantify in order to express that they feel the relationship is a healthy and viable one.

PRAGMATIC VS. PROCESS ORIENTED

The purpose of communication, for many Americans, is pragmatic.(Ramsey and Birk, 1983, p.252) The key to effective communication as perceived by Americans is the accomplishment of the intended goal-- the end result. For Japanese, however, the process of reaching that end result is of equal importance to the end result.

\section{Japanese Orientation}

Japanese are process oriented. The Japanese tend to focus on the means to the end, as well as the end. However, the Japanese see the solution as secondary in importance to the process. The way the Japanese approach mastering an art form exemplifies this. The Japanese pottery student never 
asks the teacher how long it takes to become a master potter. There is no end to the training and learning process.

The Japanese emphasis on process in their interaction format relates to the indirect approach of the Japanese. Japanese are more likely to present their ideas in a circular fashion, concerned with coming to some sense of mutual agreement or empathetic feeling. The Japanese process orientation toward communication allows for the cultivation of empathy and sharing of moods (Barnlund, 1975, p. 166).

American orientation

The pragmatic orientation of Americans causes Americans to emphasize the end. For example, Americans usually want to get down to solving the problem. American students studying pottery in Japan have often asked questions like "When will I be able to make a bowl", etc. They are more interested in the end product, than they are in the process of its creation.

The American pragmatic approach is related to the American direct communication style. Americans terd to present their ideas in a linear fashion with the focus being on the end result. This pragmatic approach encourages the exploration of differences and the respect for argument from which comes some ageeable solution (Barnlund, 1975, p.166). 
Intercultural Marriage Application

When an intercultural couple is attempting to work olt a problem through discussion they may have difficulty because of varied approaches and because expectations of what should result from the discussion may differ. An American person, who tends to use a pragmatic approach, will be interested in the end product or solution and the steps necessary to reach that solution. A Japanese, on the other hand, will not only be interested in the result, but also in how the process of discussing allows for an empathetic feeling to evolve. 
CHAPTER IV

\section{METHODS AND PROCEDURES}

PROCEDURAL OVERVIEW

The interview method was used to gather data indicative of problematic cultural differences. Subjects were chosen according to four criteria--nationality, make-up of couple, age, and length of marriage. Twenty-four subjects were selected for the interview. The group of interviewees was relatively homogeneous in terms of professional status, education and intercultural experience. The interview schedule questions were generated from a number of prelimanary interviews and from the cultural differences explored in the literature. The questions and sequence of questions were consistent in all of the interviews. The interviews normally took place in the homes of the interviewees or an eating establishment and ran about one and a half hours. An informal content analysis was done to convert the raw data into the form that it is reported out in the results. 
THE METHOD

The interview method was chosen to facilitate the gathering of information and examples directly from individuals engaged in intercultural marriages. In agreement with Tucker (1981), I felt that the "naturalistic inquiry" would aid in gathering the most detailed and pertinent information. Tucker defines naturalistic research in the following:

A naturalistic researcher says the knower is inextricably a part of what is known. The naturalistic researcher questions the assumptions that others take for granted; he or she is interested in people's logics of their own constitutive actions; he or she seeks the actor's, not the researcher's, interpretations or meanings (p. 119).

This is the precise nature of this study. It attempts to check whether the assumptions made about cultural differences hold true in an intercultural marriage context. To this end, the study attempts to explore the interviewees' perceptions concerning their own intercultural marriage and what they perceive as being problematic cultural differences.

The naturalistic method is approriate to "personal" areas such as marriage because it relys on individuals' logic of their own actions, rather than the formal logic of the researcher.

The interview technique associated with the naturalistic method is appropriate for this type of study because it can capitalize on the personal relationship the 
researcher has with her interviewees. People normally do not freely talk with strangers about problems in their marriage. However, my personal relationship with many of the interviewees, as well as my being in an intercultural marriage myself, allows for a situation where the interviewees can feel comfortable in sharing personal information.

\section{CRITERIA USED IN SELECTION OF SUBJECTS}

The subjects were chosen according to the following:

1. In order to have subjects represent Japanese and American cultures respectively, Japanese subjects who were born and raised in Japan and American subjects who were born and raised in the U.S. were selected.

2. In order to determine if the male-female factor had any effect on what cultural differences were perceived as problematic, six couples of each combination-- Japanese husband/American wife and American husband/Japanese wife-were selected.

3. In order to have a consistent group the age of the subjects was limited to between 25 and $4 \varnothing$. However, of the 24 people interviewed one American husband was only 20. I will consider this discrepancy in my analysis of the results.

I chose to exclude the so called "war bride" marriages because they tend to represent a different group. According 
to various studies, the Japanese wives, knowing that they would permanently leave their country to reside in the U.S. seemed to have had made the adjustment quite readily to being married to an American and life in the U.S. The studies reported that one problematic area in the marriage was the financial standing of the husbands. (Schnepp, 1955; Worden, 1951; Strauss, 1954).

4. In order to insure the interviewees' ability to discuss the expected problematic cultural differences I had originally planned to select couples who have been married between one and five years. This choice was based on a number of informal preliminary interviews, the results of which indicated the following: Less than one year may not be long eoungh for a couple to sift through all the adjustments that come with being newlyweds and distinguish the problems which had their roots in cultural differences from those that didn't. Those married more than 5 years would be more likely to have adjusted to the cultural differences and, therefore would not be as aware of their presence. However, due to the lack of availability of couples who satisfied this condition I included three couples married more than 5 years. One couple was married fourteen years, a second couple was married ten years, and a third coulple was married seven years. I will consider this discrepancy, too, in my analysis of the results. 
THE SUBJECTS

Twelve couples in intercultural marriages who reside in the U.S. were interviewed in this study. Six of the couples were composed of an American husband/Japanese wife, and the other six couples were composed of a Japanese husband/American wife. I knew eight of the twelve couples before I began the study ard the remaining four couples were introduced to me by friends. All but one of the subjects was a college graduate. Many of them are professionals, including an accountant, a city planner, seven teachers, two office managers, an international marketir.g developer, a computer programmer, and two travel agents. Half of the couples own their homes and the other half are renting. Although the extent of the subjects intercultural experience varies, all the subjects have had some living or traveling expereince in their spouse's native country.

I insured the interviewees that their responses would be confidential due to the personal nature of the interview. I will, therefore, not include a transcription of the respondents' answers but will illustrate the kind of raw data collected with quotes in my analysis of the results. The subjects will be referred to by nationality, sex, and an assigned number. For example, the first Japanese female interviewed will be referred to as JFl. Her spouse will be referred to as AMI. 
THE INTERVIEW SCHEDULE

The interview schedule (refer to pp. 65-69) was created to elicit information from the interviewees concerning cultural differences which they felt were problematic or, at least, that required adjustment. The questions were generated, in part, from the informal preliminary discussions I had held with intercultural couples and my personal experience in an intercultural marriage. Over the last three years I have had an ongoing diologue with friends concerning both the benefits and difficulties they are experiencing in their intercultural marriages. I also talked with couples who had been in a Japanese/American intercultural marriage, but were now divorced. They shared their perceptions and feelings as to why they felt the marriage had failed. Many of their comments indicated that the conflicts they encountered were rooted in the cultural differences under exploration in this study. Using these discussions as a foundation, I selected cultural differences explored in the literature review and created interview questions that explored those areas.

The subject matter of each question is designed to be pertinent to the cultural difference under exploration. The questions ask about behaviors that in all cases have been noted by researches as indicitive of a particular value orientation or communication style. As such the interview questions can be assumed to have "face validity". Lindeman 
(1979) defines face validity as follows: "Face validity refers to the degree to which each item in a test appears, 'on the face of it', to be approriate for inclusion in the test, ie., to belong in the test" (p.48).

The questions are arranged in groups. There are four questions about value differences, six about communication style differences, and one general question. The questions and sub-questions are categorized according to the cultural difference. Questions to which I anticipated having to give clarification and examples, have a brief explanation after each.

Questions targeted at the first value category--group vs.individual--inquire about behaviors which exemplify group and individual orientation differences. For example, whether you have a group or individual orientation will influence who you go to for help (Condon and Yousef, 1975, p.75), which served as the basis for the question of where you would turn if you needed a loan or counseling for marital problems. The other two questions relate to the idea discussed in the literature review that in Japan, unlike in America, individual happiness is secondary to the well being of the group or family unit (Gewirtz, 1983, 25). The questions in the second group of value oreintation--dependence vs. independence--ask specifically about actions of dependence and independence. The literature suggests that the Japanese actions of "amae" or 
dependence may conflict with the American emphasis on independence and self-reliance. Much of the material for the questions in this categroy was generated from studies done by Gewirtz (1983) who has counseled individuals in American/Japanese intercultural marriages.

The aim of the questions in the third value category is to elicit responses from the interviewees regarding the underlying difference between the American ideal of equality and the Japanese emphasis on hierarchy to determine if this cultural difference was problematic. Some of the actual material in the questions is taken from Haglund (1984) who states that in Japan "A wife must subordinate her will to the authority of her husband". Other material used in the questions is from Buck's (1984) work on the different views of independence and obedience in America and Japan.

The questions for the last value difference-undefined and defined sex roles--were generated from comments made in the prelimenary interviews and the research of Brannen and Ramsey (1979); and Vogel (1978). In their studies they basically described the typical sex roles in Japan and contrasted those with roles in America.

The questions for the first category in communication style were largely derived from the work of Kunihiro (1975). He illustrated how the Japanese interpersonal orientation and the American individualistic orientation was reflected in their respective communication styles. The interview done by Bodger (1984) with a Japanese/American intercultural 
couple also provided material for the questions in this category. The Japanese woman complained that it was difficult to express her opinions and the American husband found this frustrating.

The questions for the second group--subjective vs. objective view of reality--were in part generated from the work of Lebra (1976) ard Ramsey and Birk (1983), whio illustrated the importance of social relations in the Japanese view of reality, in contrast with the American belief in linear determinism.

Questions for the third category in communication style-- language differences-- came partly from my personal experience communicating with Japanese and in teaching English to Japanese and from material in Ramsey and Birk (1983).

Questions regarding the fourth communication style difference--emphasis of verbal language vs. emphasis on nonverbal communication-- were in part derived from Hall's (1976) analysis of low and high context cultures and on Bernstein's (1964) description of restricted and elaborated codes. Some of the actual material for the questions in this category came from information obtained in the prelimenary interviews.

The questions in the fifth category--harmonize vs. persuade--were generated from descriptions of the American persuasive style and the Japanese harmonistic style 
(Naotsuka and Sakamoto, 1981; Ramsey and Birk, 1983; and Kunihiro, 1976).

The questions in the sixth category which deal with the communication style difference of holistic vs. quantiative interaction format are generally derived from the ideas presented in Ramsey and Birk (1983) regarding the American quantitative approach and from okabe (1981) regarding the Japanese holistic approach.

Questions for the seventh category--process vs. pragmatic--were generated from both personal experience and from and from Barnlund's (1975) description of Japanese and American communication style which set up the difference and consequently, the possibility for conflict in an intercultural marriage.

The interview ended with a general question which allowed the interviewees to highlight the area they felt tended to produce the most conflict or called for the most adjustment.

TIME, LOCATION, AND INTERVIEW SESSION

The length of each interview varied, but the average was one and a half hours. The interviews were held in the homes of the interviewees or in some sort of eating establishment. The atmosphere was cordial because of my personal relationship with most of the interviewees. They expressed enthusiasm about the questions and were quite willing to share their thoughts and feelings regarding the 
questions. I feel part of this willingness was due to the friendly nature of our relationship and also because the interviewees felt they could be more open with me knowing that I too was in an intercultural marriage.

All but two couples were interviewed separately because I felt that the participants would be more open and willing to share information if they were not interviewed with their spouse. Two couples were interviewed together because of the wives' insecurity about their English. This discrepency, like the other two, will be considered in my analysis of the results.

The same questions and sequence of questions were consistently asked of each individual. The questions served as a guide for me as I conducted the interviews, but I made some adjustments to make the interview session more conducive to sharing information. For example, I almost always referred to the interviewee's spouse by name, rather than by the term, spouse. Also, because I knew eight of the twelve couples personally and got to know the other four couples rather quickly, I would often clarify questions with examples which related directly to the individual's situation. It allowed the interviewees to express their feeling and ideas more freely. I anticipated that some questions would need further clarification and for these I was ready to give examples. If the interviewee had thoroughly answered a question prior to being asked it, I 
would not repeat the question unless I felt the interviewee could elaborate upon it.

Though, normally, one might expect a discussion of values to be more abstract than a discussion of communication styles, I began my interviews with questions about value differences because I felt they were easier to answer. These questions seemed to allow for more concrete reflections than did the questions on communication style differences. Value differences are something that people are generally aware of, and in an intercultural encounter people normally expect value differences to exist, even when they don't know exactly what those differences will be. Communication style differences, on the other hand, have not receieved as much attention, and people are less aware of them. Communication style differences tend to be subtle, and they are difficult to talk about because one needs to be familiar with certain esoteric communication terms in order to effectively express these differences.

\section{DATA ANALYSIS}

An informal content analysis procedure was used to derive the results as they are presented in the study. The data consisted of notes taken during the interviews.

The interviewees' responses were recorded onto a matrix. The matrix had a column for each interviewee and a row for each cultural difference. Each interviewee's 
response concerning each cultural difference was recorded in an individual cell. Responses were recorded as being either problematic or not, and if they were problematic, the reasons and examples illustrating the problematic nature of the cultural difference were recorded in the corresponding cell. On this matrix the responses were analyzed and quantified. The number and percentage of individuals who reported a problem for each cultural difference was tallied and recorded in the results. Explanations and examples given by interviewees were used as a check for consistency in their definition of "problem". Among those who reported problems, in each case, the ratios of Japanese to Americans and males to females were recorded. 
INTERVIEW QUESTIONS: CULTURAL VALUE DIFFERENCES

VI. GROUP VS. INDIVIDUAL

1. If you were in need of a loan, for example, a down payment on a house, would you prefer to go to a bank or ask a family member?

Would you be more likely to go to a counselor or a family member if were you having serious marital problems? Do you or your spouse differ on who you prefer to go to for help? Does this ever cause problems?

2. Do you think it is important to have time and activities for your self separate from your spouse? If so, if your spouse puts time constrains, or some other limitation on you which prevents you from continuing your own activities, are you willing to give them up? If so, do you feel frustrated? If not, does your spouse become annoyed? Does this ever cause tension in the relationship?

3. Do you have individual goals that conflict with the goals of you and your spouse as a couple? (For example, writing this thesis limits the time and energy I have to spend on taking care of our business and the house.) Do the conflicting soals ever cause tension in the marriage?

\section{DEPENDENCE VERSUS INDEPENDENC:E}

1. How do you feel about the following: A Japanese expects to be able to "amaeru" to his/her partner. It signifies a special closeness and a kind of love. (This question is given to provide a means of coming to some concensus on the meaning of "amaeru" as it is used in this research.)

2. Do you feel your spouse is too dependent on you for certain things? Does you spouse's actions of "amae" bother you? Do you wish your slouse was less independent? Does it bother you to see that your spouse does not depend on you for his/her emotional and physical well being?

3. Directed toward couples where the husband is Japanese: Do you think the following depicts the actions and feelings of you and your spouse? "A husband may act in a childish way as a sign that he wishes his wife's indulgence. An American wife often does not appreciate this "amae" and resents her husband's requests to draw his bath or cook his late night meals. She does not bask in its sweetness like her Japanese counterpart." If so, does it create problelms in the marriage? 
VIII. INEQUALITY VERSUS EQUALITY

1. Do you, or your spouse, tend tc be more domineering in the relationship? Do you ever have problems regarding this? (Anticipate having to clardfy with examples.)

2. Do you or your spouse ever have differences regarding the heirarchy of authority between yourselves?

3. Directed toward the wives interviewed: Do you ever have to subordinate yourself to your husband? In other words, must you abide by what your husband says regardless if you agree or not? Directed toward the husbands interviewed: Does your wife subordinate herself to you? Does it bother you?

VIV. SEX ROLE VALUES

1. Are you and your spouse's roles clearly defined? What roles do you play, ie., husband/wife, housekeeper, breadwinner, child care giver, professional...? Are you comfortable with all your roles? If not, does this cause tension in the relationship?

2. Does your spouse satisfactorily fulfill the roles you expect of him/her? If not, is this a problem in the relationship? 
INTERVIEW QUESTIONS: COMMUNICATION STYLE DIFFERENCES

ORIENTATIONS TO INTERACTIONS:

CI. INTERPERSONAL VERSUS INDIVIDUALISTIC

1. Do you tend to assert your individual opinions and feelings regardless if they are in agreement with your spouse?

Or, are you careful to consider how your spouse will respond to an opinion or feeling you have, prior to speaking out?

2. Does your spouse express his/her opinions as much as you would like?

3. Do you feel your spouse talks too much about him/her self?

CII. SUBJECTIVE VERSUS OBJECTIVE VIEW OF REALITY

1. Do you tend to rely on objective facts to determine the truth about something? Or, are you more inclined to rely on the situation and the people involved? (Anticipate having to to give examples to clarafy question.)

2. Do you or your spouse think in terms of dichotomies, ie., yes or no, right or wrong, or are you or your spouse more inclined to think in terms of a continuum? In the later case you would be more likely to say "it depends" rather than giving a yes or no answer. If you ard your spouse differ on the above does this cause problems when trying to communicate?

CODE PREFERENCE:

CIII. VERBAL

1. What language do you use with your spouse? If you use both, what percentage do you use of each? Are you comfortable with the languages used, or is there some problem due to lack of fluency either cin your part or on your spouse's?

2. Does the language itself ever cause communication problems between you and your spouse? If so, can ycu tell me in what area problems are likely to occur. (If the followirg areas are not brought out I will continue to ask the following questions.) 
3. Do some words have different meanings to your spouse than they do to you. Does this ever cause problems?

4. Do you or your spouse have difficulty conveying something because there just is no equivalent in the other language?

5. Do you or your spouse sometimes misunderstand "Japanized" English words? Is it a problem?

\section{NONVERBAL}

1. Does your spouse verbally express his/her love for you? Would you like your spouse to verbally express his/her love more/less?

2. Are there times when you wished you didn't have to explain what you wanted or how you felt to your spouse?

3. Do you usually know if something is bothering your spouse even if he/she doesn't say anything? Does your spouse ever complain that you don't notice how he/she is feeling?

4. Do ycu or your spouse use silence as a means of expressing feelings? Does this ever cause difficulty in the relationship?

5. Do you or your spouse ever use things, for example, food, the arrangement of something etc. to convey feelings? (Anticipate having to give further explanation.)

6. Do you or your spouse reveal their feelings to you through how they do something, or how something is said, rather than what they say or do?

\section{INTERACTION FORMAT:}

\section{HARMONIZE VERSUS PERSUADE}

1. Do you or your spouse tend to want to persuade the other person into agreeing with your point of view? Does this ever aggravate either you or your spouse.

2. Do you find yourself or your spouse apologizing for things you or your spouse were not actually resonsible for in order to maintain a smooth relationship? If you are asked to apologize for something that you felt you were not at fault, how would you feel? Does this ever happen? If so, does it cause problems in your relationship? 
CVI. HOLISTIC VERSUS QUANTITATIVE

2. Do you find that your spouse is too analytical or not analytical enough?

3. Does your spouse sometimes seem not to follow your logic, or do you sometimes find him/her illogical?

CVI. PROCESS VERSUS PRAGMATIC

1. In working out a problem or when trying to make a decision does your spouse seem to be concerned with the end result more than the discussion at hand? If so, does this cause some difficulty communicating?

2. After you have discussed something do you feel that you and your spouse are able to set down some objectives and steps necessary to reach some goal? If not, does this cause any tension in tre relationship?

GI. GENERAL QLIESTION

I. In what area do you find that you and your spouse have the most conflicts, or in what area do you have to make the most adjustments? 
CHAPTER V

RESULTS AND DISCUSSION

In this chapter the interviews will be analyzed and discussed in terms of their consistency with the expected problematic cultural differences which were outlined in the literature review. The total number of interviewees who reported difficulty with each a cultural difference will be recorded, then categorized according to nationality and sex. These figures will be followed by specific examples from the interviews.

CULTURAL VALUE DIFFERENCES

VI. Group vs. Individual

Seventeen out of the twenty-four individuals interviewed indicated that the cultural difference between group and individual orientations was problematic. of the 17. 9 were Japanese and 8 were American. The female to male ratio was $9: 8$.

That 718 found this cultural difference to be problematic is strongly supportive of the literature. The main area of tension involved the conflict between one spouse's personal and career activities and the couples time together for shared activities. of the four Japanese females who reported problems in this area, JF5 and JF6 wanted their 
husbands to spend less time with his personal activities and friends and more time with the wives or, in the case of JF5, tree children. "I don't like him to go hunting on the weekends with his friends...I dan't think he needs to spend so much time with his male friends" (JF6). These same two husbands, AM5 and AM6, were annoyed at times by their wives' complaints. "Our biggest conflict is over the time I spend with my friend... but I've compromised as much as I can" (AM6) •

The other two Japanese females who reported difficultyJFl and JF3-- indicated some tension in the relationship because of conflicting goals. "I'd like to continue my studies in pottery but this is difficult as a married couple" (JF3). They would like for their husbands' career goals to accomodate their personal goals. The response of these two is ambiguous in terms of whether it conforms to the Japanese cultural pattern of group orientation. The two women, JFl arid JF3, could be seen as being more individualistic in the sense that they have strong individual goals separate from their spouse. However, their willingnesss to wait for a suitable time to pursue these goals could be seen more as a tendency toward a group orientation. As was stated in the literature review, the well-being of the family unit overrides individual happiness. (Gewritz, 1983) 
This same tension of conflicting goals was felt by JF3's husband--AM3. He would prefer to have his own business, but his wife would like the security of his working for a big company.

Five of the six American females, AF1, AF3, AF4, AF5, AF6, reported having, or having had some frustration over the time their husbands spent at work and their, "tsukiai", networking activities. "His carrer goals conflicted with my family goals... he changed jobs to accomodate this". (AF4) The Japanese males, JM], JM3, JM4, JM5, JM6, felt the same tension because of their wives' requests for them to spend more time with the family. Some of them, JM4, JM5. JM6, indicated some frustration because their wives didn't seem to understand why they felt compelled to work as much as they did. "I should stay at work longer for my career, but my wife wants me home early" (JM5). This may be related to Nakane's (1970 p.127) statement that the Japanese husband is concerned with the family as a whole, which may be interpreted to mean their physical livelihood, rather than his wife and children as individuals. However, these same men felt they were making a lot of adjustments to accomodate their wives' need to have them spend more time with the wives and the children, and thus, felt less conflict than they did at the beginning of their marriage.

Finally, one American female, AF3, was annoyed at her husband for seeking help frcm her family over a disagreement the couple was having. "If we had a problem he would gc to 
my family to see what I was thinking" ( $A F 3$ ). She felt it did not concern anyone except the two of them. This area of conflict is also consistent with the literature which indicated that the Japanese tend to use the family as a frame of reference, unlike the Americans who use the self as a frame of reference.

VII. Dependence vs. Independence

Twelve out of twenty-four interviewees indicated some tension in the relationship because of the cultural difference between independent and dependent orientations. of the twelve, four were Japanese and the remaining eight were American. The female to male relationship was 4:8.

That $50 \%$ reported conflict in this area is less supportive of the literature than expected. The breakdown in terms of nationality, however, does agree with the literature. The Japanese, both male and female, expected to be able to depend on their spouses-- sometimes to a greater degree than their spouse would like. In contrast, the Americans were, at times, more independent than their spouse would like.

The majority of Japanese females interviewed expressed no difficulty with the cultural difference between dependent and independent orientations. "He doesn't 'ama€ru' too much, nor is he too independent (JF1, JF2, JF3). It is possible that these: Japianese wives appreciate their husbunds independence because, unlike traditional Japanese wives, 
all but one of these Japanese women had careers or part time jobs which may give them a greater sense of selfreliance. JF4, who didn't have a job outside the home, reported that her husband depended on her a lot, but that it wasn't a problem because she felt comfortable in that role. Age may be a factor in this, since JF4 was the oldest of the Japanese females interviewed and may belong to a different "generational culture." JF5 reported that her husband would "amaeru" too much, wanting her to give him emotional support in his personal activities. "He feels I don't encourage him enough, especially in his running" (JF5). In a sense, JF5 is indicating that she feels her husband depends on her too much for emotional support but, in another sense she is expressing her frustration over his independence. "Sometimes he is too independent...his personal interests have priority" (JF5).

In contrast to the Japanese wives, five of the six American males interviewed, AM1, AM3, AM4, AM5, AM6, expressed that at times their Japanese wives depended on them too much, either emotionally, or for help understanding certain American institutions and systems. "She wants me to make phone calls and contacts for her" (AM5). These American males believed that their wives' actions of dependency were caused by the fact that America was a foreign country to them. "I think when you are in a different country you depend on the one whose country it is"(AM4). 
Two of the three American females, $A F 2$ and AF5, stated that their husbands were sometimes too dependent on them for their physical needs, and AF6 complained that her husband was sometimes too dependent emotionally. "He acts like a little boy sometimes" (AF6). Few American wives expressed that their husbands depended on them too much, or to the degree expected from the conclusions drawn in the literature review, but the fact that the Japanese husbands married an American and are living in the U.S. indicates that they are relativley independent Japanese men.

Supportive of the literature review were the Japanese husbands, JM2 and JM5, who complained that their wives were too independent-- "Why can't she just rely on me? I want her to disclose her weaknesses or insecurities and rely on me" (JM5).

VIII. Inequality vs. Equality

Eight of the respondents indicated that the difference between the value of equality and the value of inequality, or the Japanese notion that the husband should have the authority in the relationship, proved difficult. Of the eight, five were Japanese and three were American. The female to male ratio was $4: 4$.

This 338 is not suportive of the literature, but again it is consistent in terms of the make-up of the couples. Reporting problems in this area were seven individuals in a marriage consisting of a Japanese husband/American wife and 
only one individual in marriages of an American husband/ Japanese wife situation.

of the Japanese females only JF6 reported that her husband was too domineering, but that they were usually able to work it out and negotiate a solution. "He is more domineering and usually gets his way, but we usually sit down at the end of the month and discuss it (JF6)

Among the American wife/Japanese husband group there was more difficulty reported. Three American females, AF2, AF5, AF6, stated that in the first years of their marriage they had to get used to subordinating themselves. "I have adjusted to subordinating myself and do not find it uncomfortable to do so now" (AF2). Four of the Japanese males, JM2, JM3, JM5, JM6 said they expected their wives to be subordinate on major decisions. "The authority should be with the husband on major decisions, but everyday details should be decided by the wife" (JM2).

\section{VIV. Sex Role Values}

Nine of the twenty-four individuals reported some difficulty in regards to sex role values. There were seven Americans and two Japanese. The ratio of females to males was $4: 5$.

$38 \%$ is less supportive of the literature than was expected, but the fact that more difficulty is reported in the Japanese husband/American wife group does support the literature. 
None of the Japanese females reported any difficulty with sex role values. The two Japanese males, JM2 and JM4, however, reported initially feeling annoyed by their wives' demands for them to participate more in the household duties and child care, but are now able to sympathize."I thought about my actions of "amae" and realized I should do more around the house and spend more time with the children" (JM4).

of the American males, two AMI and AM6, wanted their wives to contribute more, fing/cially. AM3 felt that the roles concerning household duties were not defined clearly enough, he felt some frustration because things at home were rather chaotic. This is contrary to the American pattern of relatively undefined roles, but in this particular case the role definitions were extremely vague.

Four American females, AM2, AM4, AM5, and AM6, said they had to encourage their husbands to participate more in the child care and household duties, but their husbands were contributing more now than they had at the beginning of the marriage. "At the beginning he did not do enough of the child care" (AF6).

This area of sex role values seemed to be one where a lot of negotiating and compromise occurred in the beginning of the marriages, and continues only to a lesser degree. 
COMMUNICATION STYLE DIFFERENCES

CI. Interpersonal vs. Individualistic

Nineteen of the twenty-four interviewees reported some difficulty because of the different communiction styles-the Japanese' interpersonal orientation and the Americans' individualistic orientation. There were ten Japanese and nine Americans. The female to male ratio was 9:1ø.

That 798 reported the above cultural difference to be problematic is highly supportive of the literature.

In the Japanese group, three females reported difficulty-- JF2, JF4, and JF5. They complained that at times their husbands spoke too directly to them, hurting their feelings. "He is very honest and expressive, even if he knows it will hurt me or others." (JF2) such responses are consistent with the literature. Kunihiro (1975) states that Japanese "pay attention to the adjustment of human relations", and they are wary of expressing their opinions too strongly. This is not the case with Americans, who are inclined to express their opinions openly.

Two other Japanese females, JFI and JF6, expressed their frustration that their husbands were not as expressisve about their opinions and feelings as they would like them to be. "I often find myself criticizing him for not being expressive enough" (JFI). JFl's and JF6's responses, concerning the stoicism of their American 
husbands were not consistent with the American individualistic orientation. JF6, however, responded that her husband was not expressive enough with her, but he talked openly with his male friends. This could be due to the short time this couple has been married.

The five Japanese males-- JM1, JM3, JM4, JM5, JM6-- on the other hand, reported that they felt their wives talked too much, especially when there was another Japanese male present. "She talks too much in general and I sometimes feel she's "urasai", (noisy and bothersome), especially with my business associates"(JM5). Although not reported directly from JM6, his wife reported that he did not like her to assert her opinons and he would try to instruct her to do otherwise, with comments such as "Why don't you say it this way" (JF6).

In the American group five American males-- AM2, AM3, and AM4-- indicated dissatisfaction with the amount of selfexpression on the part of their wives. "She is not expressive enough... I expected her to be more open since she's lived in the U.S. so long" (АM3). AM6 said his wife was too talkative, and AM5 said his wife was too introspective. The later thought his Japanese wife talked too much about the trivial happenings of her day, but also sympathized with her need for some communication with adults since she was home with the children all day. 
The four American females-- AF1, AF3, AF4, and AF6-complained that their husbands were too stoic and did not express their feelings enough. "I get mad because he won't talk about work " (AF6).

The responses, in general, tended to be consistent with the literature review, especially in the Japanese husband/American wife situations, and particularly in the case of American females when other Japanese males were present.

C.II Subjective vs. Objective

Twenty of the twenty-four respondents reported having difficulty because of the subjective/objective cultural difference. Of these twenty, ten were Japanese and ten were American. The female to male ratio was $1 \emptyset: 1 \emptyset$.

This $83 \%$ is highly supportive of the literature. All of those who reported having difficulty told of having to make adjustments to the differing ways of viewing realityeither subjectively or objectively.

of the five couples in the Japanese wife/ American husband group, four couples-- JF1-AM1, JF2-AM2, JF4- AM4, JF5-JM5-- indicated some degree of difficulty because the husbands were more dichotomous in their thinking than the wives, leading the wives to feel pressure from the husbands to give clear cut answers. "Sometimes his dichotomous thinking seems pushy" (JF2). The exception was AM3, who reported having difficulty because his Japanese wife became 
frustrated when he wanted to adjust his opinion or rethink over a decision that they had made. She wanted to go with whatever decision had been made. In this situation the Japanese woman is following a dominant American cultural pattern--"erabi"-- and the American is following the more dominant Japanese pattern-- "awase".

In the American wife/Japanese husband group there was a mixture of responses regarding the first and second interview questions in this category. However, the responses were consistent with the cultural patterns discussed in the literature review. The Japanese were seen as being more subjective than the Americans. A common complaint by the American wives-- AF1, AF3, AF5, AF6-- was that it was sometimes difficult to plan because they could never get definite answers from their husbands. "I want to have everything planned, but he wants to be flexible" (AF3). In contrast, the Japanese felt frustated by their wives requests for definite answers.

Many Japanese husbands complained that their wives did not understand the importance of social relationships and how they are often more important than objective facts. For example, JM4 wished his wife could understand why he based his decisions regarding work on what people would think, and on particular relationships, more than on objective facts. "She didn't care what my boss would think if I quit my job, she only saw that I was overworked" (JM4). 
This tension also works in reverse. An American wife, AF5, expressed frustation because she couldn't understand why her husband's personal relationship with someone else should have any effect on decisions that involved only the two spouses. AF5 related the story of shopping for a piece of furniture for the family. Instead of buying what was "objectively" the best, the husband based his decision on a guest's remarks. He based his decision on a personal relationship, rather than on the facts. Another example of this is JFl-JMl's experience buying a car. The wife presented the objective facts as to why they should buy the car, but the husband thought that he shouldn't buy the car because it was "tco good"(JMI). He thought that because he was a "poor student" he shoud not have a nice car, even though it was a good buy and he could afford it.

\section{Verbal Code}

of the twenty four individuals interviewed, all said that language itself was not very problematic. The fact that Ø용 reported a continual problem with language is supportive of the conclusion drawn in the literature review, that verbal language would not be as problematic as nonverbal language. Language may have been problematic at the beginning of the relationships, but the couples were able to adjust to the language differences relatively quickly. of course, all couples related times when they had misinterpreted each other because of unfamiliarity with a 
phrase or a word, but they realized immediately that language was at the base of the conflict and were soon able to rectify it.

We had lots of problems at the beginning because we would misunderstand the nuance. Now it is much better. We know it is a language problem. Before we would just continue to fight (AF6).

None of the interviewees indicated any specific problems with language, such as lack of equivalents, words having opposite meanings, etc.

Difficulties were more often attributed to general misunderstandings. The difficulties reported often revolved aroud how something was said rather than what was actually said. This is an example of difficulties being a result of the cultural difference in nonverbal usage rather than in language, specifically.

\section{Nonverbal}

Eighteen of the twenty-four individuals interviewed reported having difficulty with the difference between Japanese and Americans in nonverbal usage. Of the eighteen there were nine Japanese and nine Americans. The female to male ratio was $9: 9$.

That $75 \%$ of those interviewed reported problems relating to nonverbal usage is quite supportive of the the literature. The responses were consistent with the literature review in all but one case. 
Though the Japanese generally indicated that they emphasized nonverbal communication rather than verbal communication and that they often conflicted with their American spouses in this way JF6 did complain that her husband wasn't as verbally expressive with her as she would like. Her American husband, in turn, felt she was too verbal. However, the wife said that he was very open and talkative with his friends, so the possibility that he wasn't openly expressive with her could be due to his young age, or to the short time they had been married. JF6 reported that her English teachers and other Americans had told her that she needed to verbalize her feelings and needs if they were to be met by her American husband. All but this Japanese female reported that they didn't want to have to explain how they felt and that they wished their husbands receive the nonverbal behavior signals or would "just know". They were frustated with the amount of verbalization their spouses needed to understand them, and often they were annoyed at the "information gap", or cultural gap, between them.

The American husbands, in turn, were at times irritated by the vagueness on the part of their spouses.

The Japanese males reported feelings similar to those of the Japanese females. They reported feeling uncomfortable at having to express their love verbally at their wives' request. "Why do you have to say it? You show it by the things you do" (JM5). All of the Japanese men indicated they 
were making an effort to accomodate their wives' need for verbal reassurance of their love, but they were still not completely comfortable.

The two American males who indicated difficulty in the area of nonverbal communication complained that their wives were silent when bothered by something. "I expected her to be more open since she lived in the U.S. so long" (AM3).

All but one of the American females interviewed reported that they had to make a considerable adjustment to their husbands emphasis on nonverbal communication. "He uses nonverbal signs when something is bothering him, but I don't know what is wrong, and I wish he would express more" AF4). They tried to both use more nonverbal means of communicating and to be more aware of their husbands' use of nonverbal communication. The area of nonverbal communication was one area where the majority of those interviewed mentioned they were working to be more sensitive to their spouse's style in order to facilitate better communication.

CV Harmonize vs. Persuade

Nine of twenty-four interviewees responded that the Japanese harmonizing style of interaction conflicted with the American persuasion style. of the nine, six were Japanese and three were American. The female to male ratio was $5: 4$. 
That only $37 \%$ reported having conflicts in this area is less supportive of the literature than was expected. However, the problems which were reported are consistent with the literature, with Japanese being more harmonistic in their interaction format than the Americans who tended to be more persuasive.

Two Japanese females-- JF5, JFl-- complained that their husbands did not use apologies as a means of avoiding conflict. "He doesn't apologize and this is our biggest area of conflict" (JF5). JF3 was sometimes bored by her husbands persuasive manner of expressing his ofinions.

Of the three Japanese males who reported difficulty, JMI and JM5 complained that their wives' persuasive style of communicating was at times "urasai"-- annoying. JM5 also indicated that he would like his wife to use apologies more.

The one American male. AM5, who indicated difficulty, AM5, responded to his wife's insistance that he apologize in the following manner: "It's not telling the truth if I apologize when I don't have any reason to apologize." The two American females-- AF4, AF5-- didn't want their husbands to use apology as a means of avoiding a conflict. "He wants to keep peace, but I want to work it out" (AF4). "My husband encourages me to apologize, but it's dishonest. It's not dealing with your true feelings" (AF5).

The nature of these responses is strongly supportive of the findings in the literature review. All of the Japanese who reported difficulty were having difficulty 
because their harmonizing style of interaction format was in contrast with their American spouse's persuasive style.

\section{Holistic vs. Quantitative}

Six of twenty-four interviewees responded that the difference between a holistic interaction format and a quantitative one was at times problematic. of the six, three were Japanese and three were American. The female to male ratio was $5: 1$.

This $25 \%$ is less supportive of the literature than was expected. The responses, however, were consistent with the differences discussed in the literature review.

The Japanese-- JM6, JM1, JF3-- indicated they felt their spouses were too analytical at times. "She is too analytical..breaking down things too much... how you feel is more important than analyzing"(JM6). Again, Americans tend to feel more comfortable evaluating an event with numbers, than with "feelings".

The three Americans-- (AF2, AF5, AF1-- reported that their husbands' logic, because it was not analytical, was sometimes difficult to follow. "Because of his different logic patterns I need more verbalization by my husband' (AF2). "I can follow my husband's logic now, but at first it was time consuming and frustrating" (AF5). AF5 has been married for 10 years, and has had necessary time to adjust to their different thinking patterns. AFl, who has been married four years, understands the difference, but still 
finds it sometimes frustrating. "He seems illogical sometimes because his reasoning is based on emotion rather than logic" (AF1).

\section{Process Vs. pragmatic}

Eight of the twenty-four individuals indicated that the difference between being process oriented and being pragmatic caused some difficulty. The group consisted of four Japanese and four Americans. The female to male ratio was $5: 3$.

Again, that 33\% indicated this difference to be problematic is less supportive of the literature than was anticipated. However, in terms of the Japanese and American groups, the responses are consistent with the respective cultural pattern outlined in the literature review.

Two Japanese wives-- JFl, JF3-- said their husbands focused on the end result, and were not involved in the process of discussing as much as the wives would like. "It's sometimes frustrating because he focuses on the end result, rather than the discussion at hand" (JFl).

The Japanese husbands, JM3 and JM5, said their wives came to conclusions too quickly. They complained that the wives didn't spend enough time in the process before reaching a conclusion. One Japanese husband consistently asked his wife, "How can you be sure?" (JM3), because he felt she jumped to conclusions too quickly. 
In the American group, AMl complained that his wife was too involved in the process and that she thought too much about things. The three American wives-- AF1, AF3, AF5-reported that their husbands were at times too process oriented. "He takes time to go through things...he goes through the process in his own mind" (AFI). "Decision making is a long process which is frustrating" (AF5).

\section{GENERAL QUESTION}

The general question generated an array of responses, but the majority of them highlighted an area that had been touched on previously in the interview. The responses that were not directly connected to the cultural differences outlined in the interview questions involved relationships other than the relationship between husband and wife. Couple JF4-AM4 indicated that the children's discipline was a problem. The American husband wanted the wife to be more authoritarian, and the wife wished he could be less authoritarian. It is not clear if this is consistent with the expectations based on the findings in the literature review. One explanation which is consistent with the literature is that the wife encouraged her children to be more dependent than her husband liked, and he encouraged them to be more independent than his wife felt comfortable with. 
One of the Japanese wives, JF3, reported that her husband's family posed the greatest conflict in her marriage. His family members did not comply to traditional roles, for example, the husband's father would come to them for advice and his older sister would request loans. The Japanese woman felt uncomfortable with these roles which seemed deviant from her Japanese perspective.

A Japanese man, JM5, also reported having difficulties with his in-laws because of the difference between dependent and independent orientations. He felt uncomfortable because he could not depend on his wife's family as he could if his in-laws were Japanese. As was mentioned earlier, JM4 reported having the most difficulty when he and his wife interacted with a third person who was Japanese. At that time re expected his wife to more closely follow Japanese cultural patterns.

In general, communication style differences seemed to be reported as being the most problematic. JM6 summarized some of these difficulties in the following:

You have to be honest in English. You must state your opinions and say yes or no. It is always I think or I feel. In Japan it is different...everyting is coated".

JM1, AF6-JF6, JF1, JF2-AM2, all reiterated that the difference between the amount of verbalization, or the Japanese emphasis on nonverbal communication, caused the most tension or required the most adjustment. JF5 also reported a communication style difference as being the most 
problematic. She highlighted that her spouse's refusal to use apology as a means of smoothing over difficulties produced the most tension in the relationship.

One other area that was cited as being the most problematic was the cultural difference in dependentindependent orientations. AF6 and AM6 both found that their inclination to be independent, to the disapproval of their spouses, caused conflict in the relationship.

Finally, partially linked to the cultural difference is expected roles, two American women-- AFl and AF5-- said that the area which was most problematic was their different expections concerning their social lives with their spouses. They would like to sperd more time with their husbands separate from the children. The husbands, however, did not feel this need. 
CHAPTER VI

SUMMARY AND CONCLUSIONS

SUMMARY

In general, results of this study, in terms of cultural differences, were consistent with the expectations discussed in the literature.

The highest percentage of reported problems was concerning the difference between the objective view of reality held by Americans and the subjective view of reality held by the Japanese. Eighty-three percent of the interviewees commented on the difficulty this cultural difference presented and the adjustments they had to make because of it. Interestingly, I had anticipated this area to be one of the most difficult in which to elicit responses. It is relatively abstract and not an area that one normally thinks about, yet interviewees indicated that this cultural difference is indeed problematic. One's view of reality is, essentially, the basis for one's thought proceses and, consequently, one's actions. This cultural difference, then, appears to have the potential for being problematic in an intercultural marriage.

The difference in the group orientation in the Japanese culture and the individualistic orientation in the 
American culture caused a number of problems and required a number of adjustments.

Seventy-one percent reported problems arising from the difference in values-- group orientation versus individual orientation--and seventy-nine percent reported difficulties arising from the difference in communication style-interpersonal orientation to interaction versus individualistic orientation to interaction.

The least problematic of the cultural differences explored was the verbal language difference. Virtually $\emptyset \%$ reported that language was an ongoing or serious problem. This is not surprising when one considers that language differences are obvious and lend themselves to an easy and quck adjustment. Because it does pose an obvious problem, a language difference receives immediate attention, unlike some of the others, but, perhaps, more problematic cultural differences.

The difference between the use of nonverbal communication, however, was reported as being especially problematic. Problems arose, not from verbalization itself, but from the amount of verbalization the spouses were comfortable with. In general Americans value talk more than Japanese do. "When my wife asks about my day I usually reverse the question and ask her about her day so I don't have to talk" (JM6). It was not only the amount of verbalization which caused tensions but the different ways that Japanese use nonverbal communication. Seventy-five 
percent of the interviewees expressed difficulty in adjusting to this cultural difference.

It is in some ways surprising that the cultural differences discussed in the literature apply so readily to an intercultural marriage. One would expect that those individuals engaged in an intercultural marriage would deviate from the dominant cultural patterns and therefore, would not be as likely to encounter the discussed problems with cultural differences betweeen the Japanese and Americans. For example, in marrying an American a Japanese is threatening his or her position in the group. This implies that Japanese who marry Americans are less concerned with the group than other Japanese, exemplifying their deviance from the dominant Japanese group orientation.

The results of this study show how influential culture is in shaping a person to reflect the particular values and communication style of that culture.

Considering the number of cultural differences the Americans and Japanese face in their marriages, it is surprising how well they have adjusted.

\section{EFFECTIVENESS OF METHOD}

The naturalistic inquiry appeared to be an effective method in obtaining information for use in this study. It seemed to facilitate the kind of personal introspective sharing of material that was called for in this research. 
As Tucker states (1979), the naturalistic inquiry is seen as a means of studying "phenomena that exist because people define them as real, for example, definitions of situations, socially contructed meanings, or interpretations of events or social institutions" (p.119). This is in essence what the interviewees were doing. They defined and reported on problematic cultural differences as they perceived and interpreted them.

This study also seemed to illustrate the point made by Kirk and Miller (1986):

We can never be absolutely sure that we understand all the idosyncratic cultural implications of anything, but the sensitive, intelligent fieldworker armed with a good theoretical orientation and good rapport over a long period of time is the best check we can make ( $p .32)$.

I feel my being in an intercultural marriage myself made me more sensitive to the interviewees situation and also made them more inclined to share their feelings knowing I could emphathize with them. The literature review provided me with the theoretical background to interpret the phenomena under study.

There were some necessary considerations and adjustments made during the interview sessions which are described below. The interview questions, themselves, were asked in order, beginning with the questions on values and ending with the general question. As was suggested in the methodology section, it did appear to be easier for interviewees to give examples of value differences than of communication style differences. At times the interviewees 
discussed or related examples that corresponded with a question not yet asked. I did not insist that interviewees answer only the question at hand. I felt I could get more accurate information if I allowed the interviwees to respond to the questions freely. I merely recorded comments as they were given and later organized them according to the appropriate cultural difference. I often referred back to statements already made by the interviewees when I reached a question which I felt related to those statements. This provided a means of clarification.

All of the questions did elicit information about the targeted cultural difference, except for the second question in the interpersonal versus individualistic orientation to interaction set. (CI-2-- "Does your spouse express his/her opinions as much as you would like?") This question brought responses about the differences between the amount of verbalization spouses felt comfortable with, and, in this regard, it is more closely related to the cultural difference of nonverbal communication.

The three questions-- "Do you or your spouse ever have differences over the heirarchy of authority in your relationship?" (VIII-2), "Do you tend to rely on objective facts to determine truth about something? or are you more inclined to rely on the situation or people involved?" (CII1),"Do you or your spouse ever use things, for example, food or the arrangement of something etc. to convey feelings? (CIV-5)-- that I anticipated having to clarify, all 
required some further explanation. I found that some of the American interviwees needed some clarification with question VII-1-- "How do you feel about the following: A Japanese expects to be able to "amaeru" to his/her partner. It signifies a special closeness and a kind of love?" Some interviewees were not familiar with the meaning of "amaeru". My assumption was that the majority of people would have been aware of this concept since it is so prevalent in relationships in Japan, but some Americans were not.

As was stated in the methods section, I had planned to interview all the individuals separately, but due to a lack of English ability on the part of two Japanese spouses, I ended up interviewing two of the couples together. This did appear to have an effect on the amount of feedback I got from one couple but not from the other. JF4 tended to defer to her husband. Also, AM4 would often answer for his wife, and when I would ask her if his interpretation of her feelings and ideas was correct she would rarely say no. The second two who were interviewed together were more open, quite often disagreeing with each other. The young age and short time of marriage of this second couple may account for this difference. There was a sense that this couple, being married just one year, was still in the discovery stage. The majority of feedback was not directed at the interview questions per se, but at the spouse's comments 
regarding a particular question. As such, the interview was, for them, a kind of "Newly-Wed Game".

Those couples married over five years seemed to be able to recall the problematic areas and the adjustments they had had to make quite readily. I did not have to ask them to reflect back on the first few years of their marriage as much as I had anticipated. The couples, naturally, would make such comments as "Now it is a lot better" or "It is easier than when we were first married". There appeared to be a tendency for the problematic cultural differences to become less difficult as time went on. Those couples married just a few years were still in the stage of negotiating compromises and working out adjustments, but the couples who had been married longer had reached a point in their marriage where they were no longer searching for necessary adjustments; they were making them.

\section{LIMITATIONS OF THE STUDY}

The method of inquiry used in this study, for all its effectiveness, does have limitations as well. First, the method of generating the interview questions relied on the interviewers own research of the literature, personal experience and preliminary interviews, and thus the interview schedule is limited.

Second, the results of the study are dependent on the interviewer's sensitivity and characteristics (eg. male/ female, age etc.). Different interviewers would not 
necessarily get the same information from the interviewees. Thus, it is difficult to establish traditional reliablity of responses.

Third, because of necessary selection of interviewees, rather than random sampling, the results of this study may not be generalizable to a larger population, eg. intercultural married couples in different geographical areas, or intercultural marriages involving different nationalities.

Fourth, although this study proved to obtain information regarding what the interviewees perceived as problematic cultural differences, it is limited in that it cannot establish causuality. Who or what caused a given event in the relationship to occur, and why, cannot be determined from this study.

Fifth, the actual interviewing process was rather lengthly and fatigue may have affected the general quality of data toward the end of the interview.

DIRECTIONS FOR FURTHER RESEARCH

Further research could clarify questions which were raised in this study. Some of these questions follow:

1. Will the responses generated from the interview differ when the spouses are interviewed separately as opposed to jointly? 
The present study did reveal differences in the type of responses received from spouses interviewed together and from those interviewed separately. The type of discussion that was generated by the spouses who were interviewed jointly differed considerably. One couple's responses were dominated by the American husband, with little conferring with the Japanese wife; the other couple engaged in lengthly diologues regarding each others' comments. It would be interesting to sytematically explore how the results would differ by comparing the responses of couples interviewed together with responses of couples interviewed separtely

2. Is there a variation in which cultural differences are problematic in a marriage when viewed over a period of time?

In this study there appeared to be a pattern of adjustment which occurred over a period of time. Those individuals married longest seemed to spend less time working out the adjustments necessary to overcome cultural differences than those couples married a shorter time. A longitudinal study which interviewed couples, periodically, over a number of years could perhaps trace a course of adjustment in an intercultural marriage.

3. Would there be a difference in the problematic cultural differences in an intercultural marriage involving Japanese and Americans if the study looked at couples living in Japan rather than in the U.S? 
Comments made by individuals in this study and the Imamura study (1986) who have spent time living in Japan as an intercultural couple, indicate that societal pressure for the individuals to conform to Japanese cultural norms created problems in the relationship.

A similar study of couples in Japan would allow one to compare results to determine if the problematic cultural differences are the same in both cases.

4. Why were the results of this study less supportive of some theoretically predicted phenomena than of others?

Research on this question could prove helpful in clarifying why certain cultural differences appear less problematic than others.

5. What type of adjustments did the couples make to overcome the cultural differences?

The spouses of these intercultural marriages have developed workable solutions to their conflicts concerning cultural differences. Identification of these adjustments will provide direction for improving other types of intercultural encounters.

6. This study could conceivably be used as a pilot study for further research in the same area.

\section{APPLICATIONS}

The research, in and of itself, proved to be an application, since it provided a learning experience for the couples interviewed. A number of interviewees stated 
that they had not thought about their marriage difficulties in terms of cultural differences, and they appreciated the opportunity to do so in the interview.

Some individuals showed an interest in what their spouses had said, and, conceivably, the findings from both individuals could be shared and used as a basis for discussion between them.

The findings from this study could also be used by marriage counselors. Two of the couples had gone to marriage counselors and, from their comments, it was apparent that the counselors were suggesting the Japanese males change their behaviors in order to accomodate their wives. The counselors advice appeared to be culturally biased. The findings of this study may make counselors aware that cultural differences underlie an individuals behaviors, and thus, are likely to play a key part in the difficulties found in some marriages.

There is a support group in Japan, Foreign Wives in Japan, which provides its members a forum for discussion. There may be a need for such a support group in the U.S. and the findings from this study could be useful in forming a support group for couples in an intercultural marriage.

An intercultural training program could be designed, incorporating some of the findings of this study. The training could be directed, not only at couples in an 
intercultural marriage, but at anyone involved in an intercultural encounter. The training would, in effect make the participants more aware of how cultural differences, specifically communication and value differences, effect face-to-face interaction. 


\section{BIBLIOGRAPHY}

Albert, Ethel M. "Value Systems". International Encyclopedia of the Social Sciences. New York: Macmillan, pp. 287-291, 1968.

Benedict, Ruth. The Chrysanthemum and the Sword: Patterns of Japanese Culture. Boston: Houghton Mifflin, 1946.

Bernstein, Basil. "Elaborated and Restricted Codes: Their Social Origins and Some Consequences." American Anthropologists. (The Ethnography of Communication Association: Special (Publication.) 66: No.6, pp.55-69, 1964 .

Bodger, Carol. "The Challenges of Cross-Cultural Marriage." Glamour, May, p.314, 1984 .

Brannen, Ann and Ramsey, Sheila. "The Red Thread and the White Kimono: Japanese Women, Omote and Ura". International Journal of Intercultural Relations. VoI. 3, pp.473-486, 1979.

Bruneau, Thomas J. "Communicative Silences: Forms and Functions". The Journal of Communication. March, p.23, 1973 .

Buck, Elizabeth, Newton, Barbara, and Muramatsu, Yasuko. "Independence and Obedience in the United States and Japan". International Journal of Intercultural Relations. VoI. 8, pp.279-3øø, 1984.

Cathcart, Delores and Cathcart, Robert. "Japanese Social Experience and Concept of Groups". In Samovar and Porter's fourth ed. Intercultural Communication: A Reader. Belmont, California: Wadsworth Publishing Co., Inc. pp.19ø-196, 1985.

Caudill, William, and Scarr, Harry A. "Japanese Value Orientations and Culture Change." Ethnology. 1:53-91, 1962.

- and Weinstein, Helen. "Maternal Care and Infant Behavior in Japan and America". Psychiatry. 32, 12-43, 1969. 
Chao, Ke-Lu and Gordon, William. "Culture and Communication in the Modern Japanese Corporate Organization". International and Intercultural Communication Annual. Vol. V, Dec., p.23, 1979.

Condon, John. With Respect to the Japanese. Intercultural Press Inc. Yarmouth, Maine, 1984.

. and Saito, Mitsuko. Intercultural Encounters with Japan. The Simul Press, Tokyo, Japan, 1974.

.and Yousef, Fathi. An Introduction to Intercultural Communication. Bobs-Merril, New York, N.Y., 1975.

Doi, Takeo. The Anatomy of Dependence. Tokyo: Kodansha International Ltd.. 1973.

- "The Japanese Patterns of Communication and the concept of Amae." Quarterly Journal of Speech. 59:1, pp.180-185, 1973.

Fieg, John and Blair, John. There is a Difference. Meridian House International, Washington, D.C., 1975.

Fontaine, Gary and Dorch, Edwina. "Problems and Benefits of Close Intercultural Relationships". International Journal of Intercultural Relations. Vol.4, pp.329337,1980 .

Gewirtz, Barbara. "So You Think You Want a Japanese Husband" The Wall Street Journal, Monday, April 18, 1983.

Golden, Arthur. "Why America Can't Emulate the Japanese". The seattle post Intelligence. Dec.5, (B3), 1982.

Haglund, Elaine. "Japan Cultural Considerations". International Journal of Intercultural Relations. Vol.8, No. 1, pp.61-75, 1984 .

Hall, Edward. Beyond Culture. Anchor Press/Doubleday \& Company, Inc., Garden City Ney York, 1976.

-The Dance of Life. Anchor Press/Doubleday \& Company, Inc., Garden Cty, New York, 1984.

-The Silent Language. Anchor Press/Doubleday \& Company, Inc., Garden City, New York, 1959.

Hawkins, Dr. James. "How Good is Your Marriage". Parade Magazine, Dec. 30, p.13, 1984 . 
Hoopes, David. "Intercultural Communication Concepts and the Psychology of Intercultural Experience." Multicultural Education: A Cross Cultural Training Approach. ed. Magaret D. Pusch. Intercultural Network, Inc. IL. pp.9-38, 1979.

Huruse, Noriko. "A Comparative Study of Communication Style in Japan and the United States as Revealed Through Content Analysis of Television Commercials." Unpublished Masters Thesis. Portland State University. 1978.

Imamura, Anne. "Charting a Course in a Fog: Husband-Wife Role Misunderstanding-The Case of International

Marriage." Unpublished Paper. University of Maryland. 1985 .

- "Strangers in a Strange Land: Coping with Marginality in International Marriage." Unpublished Paper. University of Maryland. 1986.

Johannesen, Richard L. "The Functions of Scilence: A Plea for Communication Research." Western Speech. Winter, pp. 25-35, 1974 .

Kawashima, Takeyoshi. "The Status of the Individual in the Notion of Law, Right and Social Order in Japan." The Japanese Mind. ed. Charles A. Moore. pp.262-287.

Kirk, Jerome and Miller, Marc L. Reliability and Validity in Qualitative Research. Sage Publications. 1986.

Kluckholn, Clyde. "Values and Value orientations in the Theory of Action." Towards a General Theroy of Action. eds. Talcot Parsons and Edward A. Shils. Harvard University Press, Cambridge, pp.388-433, 1951.

Kluckholn, Florence and Strodtbeck, Fred. Variations in Value Orientations. New York, N.Y.: Row, Peterson, 1961 .

Kobayashi, Yoshihiko. "Toward True International Exchange." Japan Echo III, No. 4,pp.141-144, 1976.

Kunhiro, Masao. "Japanese Language and Intercultural Communication." The Silent Power and World Role.

Tokyo: Simul press, 1976.

- "Indegenous Barriers to Communication." Etc: A Review of General Sematics. XXXL, No.3, Sept., 1975. 
LaFrance, Marianne and Mayo, Clara. "Cultural Aspects of Nonverbal Communication." International Journal of Intercultural Relations. Spring, pp.71-87, 1978.

Lebra, Takie Sugiyama. Japanese Patterns of Behavior. East- West Center, University Press of Hawail, Honolulu, HA., 1976.

Lebra, Takie Sugiyama, Paulson, Joy, and Powers, Elizabeth Women in Changing Japan. Stanford University Press, Sttanford, CA 1975.

Lindeman, Richard H. Educational Measurement (2nd ed.) Scott Foresman, and Co. 1979

Morrison, John L. "The Absence of Rhetorical Tradition in Japanese Culture." Western Speech. pp.89-1ø2, Sp 1972.

Mushakoji, Kinhide. The Cultural Premises of Japanese Diplomacy." The Silent Power: and World Role. Tokyo: The Simul press, pp.35-49.

Nakane, Chie. Japanese Society. University of California press. Berkiley. CA., 197ø.

Naotsuka, Reiko and Sakamoto, Nancy. Mutual Understanding of Different Cultures. Science Education Institute of Osaka, Osaka, Japan, 1981.

Okabe, Roichi. "Cultural Assumptions of East and West." Intercultural Communication Theory: Current Perspectives. Sage Pubications, 1983.

Ort, Robert. "A Study of Role-Conflict as Related to Happiness in Marriage." Journal of Abnormal and Social Psychology. 45 (oct.), pp.691-699, 195ø.

Ratliff,Bascom, Faye Moon, Harriett, and Bonacci, Gwendolyn. "Intercultural Marriage: The Korean-American

Experience. Social Caseworker. pp.221-226, April, 1978 .

Ramsey, S. and Birk, J. "Training North Americans for Interaction with Japanese: Considerations of Language and Communication Style." Brislin, R. and Landis, D. (eds.) The Handbook of Intercultural Training, Vol.ll Area Studies in Intercultural Training. New York Pergamon press, 1983 .

Schnepp, Gerald and Yui, Anes Masako. "Cultural and Marital Adjustment of Japanese War Brides." The American Journal of Sociology. Vol. 61, pp.48-5ø, July 1955. 
Schwab, Reiko and Schwab, Edward, Jr. "Interpersonal Values of Marital Partners." The Journal of Social Psychology, 1ø4, pp.157-163, 1978.

Stewart, Charles, Cash, Eilliam B. Interviewing Principles and Practices. Brown Co. Publishers, 1974.

Stewart, Edward. American Cultural Patterns: A Cross Cultural Perspective (2nd ed). Pittsburgh: Regional Council for International Education, 1972.

Strauss, Anselm L. "Strain and Harmony in American-Japanese War-Bride Marriages." Marriage and Family Living. pp. 99-1ø6, May, 1954.

Tamura, Hitomi. "The Japanese American Interface. A CrossCultural Approach to Discourse." Unpublished Masters Thesis. Portland State University. 1983.

Trommsodorff, Gisela. "Value Cange in Japan." International Journal of Intercultural Relations. Vol 17, pp. 337-36ø, 1983.

Tseng, McDermott, and Maretzki. Adjustment in Intercultural Marriage. Honolulu: The University of Hawaii, 1977.

Tucker, Raymond, Weaver III, Richard L., and Berryman-Fink, Cynthia. Research in Communication. N.J., Prentice Hall, 1981 .

Vogel, S.H. "Professional Housewife: The Career of Urban Middle Class Japanese Women." The Japan Interpreter. 12(1) pp.16-43, 1978 .

Worden, William. "Where are those Japanese War Brides." The Saturday Evening Post. Nov. 2ø, 1951. 